CORE VALUES DRIVING SUSTAINED ELITE PERFORMANCE CULTURES

A Dissertation
presented to
the Faculty of the Graduate School
at the University of Missouri-Columbia
In partial fulfillment
of the requirements for the degree of
Doctor of Philosophy

by

ERIC BIENER

Dr. Stephen Whitney, Advisor

MAY 2020 
Running head: CORE VALUES DRIVING SUSTAINED ELITE PERFORMANCE CULTURES

The undersigned, appointed by the dean of the Graduate School, have examined the dissertation entitled CORE VALUES DRIVING SUSTAINED ELITE PERFORMANCE CULTURES

Presented by Eric Biener,

A candidate for the degree of doctor of philosophy,

And hereby certify that, in their opinion, it is worthy of acceptance.

Professor Stephen Whitney

Professor David Bergin

Professor Matthew Easter

Professor Brandon Orr

Professor Candace Kuby

Professor Daniel Turban 


\section{ACKNOWLEDGEMENTS}

There are many people who contributed to the completion of this project and are worthy of special thanks. First, Dr. Stephen Whitney provided guidance, answered many questions, and helped keep this project moving forward toward its ultimate completion. Thank you for everything you did as an advisor throughout my time at Mizzou - specific to this project and beyond. Likewise, Dr. Brandon Orr spearheaded the sport and performance psychology specialization and provided important advice throughout my time at Mizzou; thank you for everything you've done to help me grow. Thank you to Dr. David Bergin and Dr. Matt Easter for your instruction and leadership as professors, as willing ears to offer advice, and as supervisors for graduate assistantships throughout my time at Mizzou. A big thank you goes to all of you, as well, for your generosity and assistance in making a game-changing internship opportunity become a reality. I would also like to thank Dr. Daniel Turban and Dr. Candace Kuby for the opportunity to learn from you in the classroom and for the benefits your respective expertise gave this project. 


\section{TABLE OF CONTENTS}

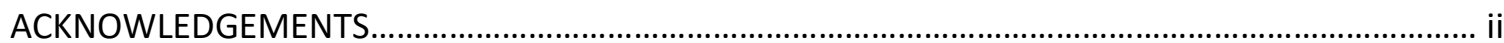

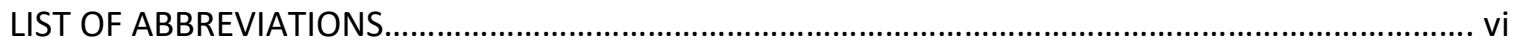

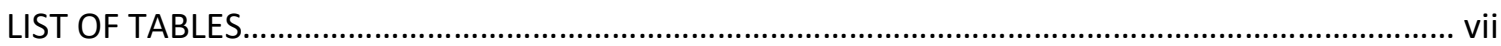

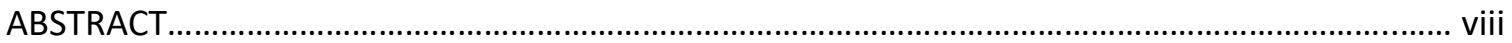

Chapter

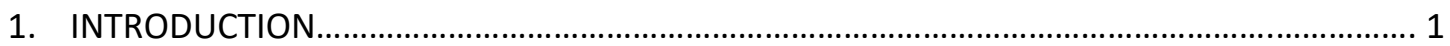

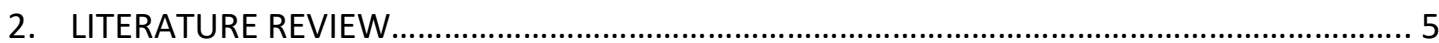

Understanding Culture Development

Culture as a Competitive Advantage?

Core Values Driving Action

Core Values Driving Leadership

Organizational Culture in Sport

Developing Culture in Sport

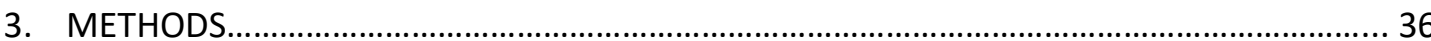

Paradigm

Tradition

Researcher's Role

Participants 
Data Sources and Collection Procedures

Analysis Procedure

Trustworthiness

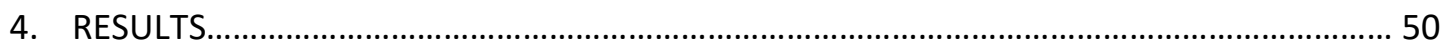

Identifying Core Values

Teaching Core Values

Living Core Values

5. DISCUSSION.

A Look at Culture and Core Values

Core Values on the Page and Into Action

Leading Through Values

Limitations

Conclusion

APPENDICES

A. Appendix A: Semi-Structured Interview Guide, Interview 1.......................................... 100

B. Appendix B: Semi-Structured Interview Guide, Interview 2....................................... 101

C. Appendix C: Semi-Structured Interview Guide, Interview 3.......................................... 102

D. Appendix D: Themes and Subthemes of Core Values for the Sustained Elite-Performing Cultures 103 
VITA 


\section{LIST OF ABBREVATIONS}

VBA: Values-based actions

VBL: Values-based leadership

NBA: National Basketball Association 


\section{LIST OF TABLES}

Table

Page

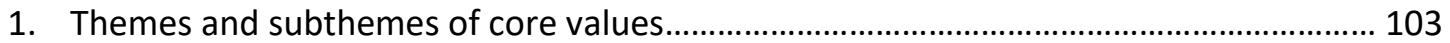




\title{
CORE VALUES DRIVING SUSTAINED ELITE PERFORMANCE CULTURES
}

\section{Eric Biener}

\section{Dr. Stephen Whitney, Dissertation Advisor}

\begin{abstract}
Organizational culture within sport has an important influence on the performance and well-being of the group and individuals. Often, cultural descriptions are based on teams' results (e.g., winning teams have strong cultures and losing teams have poor cultures). However, these after-the-fact cultural labels ignore the myriad underlying factors that contribute to the group's culture. The preponderance of organizational culture research in sport has tended to either focus on culture at the macro level (e.g., cultures of national governing bodies or athletic departments) or focus on culture change (essentially the mechanisms and processes through which poorly performing cultures changed their fortunes). However, there has been limited research looking at the cultures of programs who have sustained high-level performance for long periods of time. Moreover, there is even less research looking into the core values of such programs, one of the three levels of Schein's (Schein, 1990; Schein \& Schein, 2017) culture analysis model. Therefore, this phenomenological study aimed to understand the perceptions and experiences of head coaches in leading and developing their sustained elite-performing cultures; specifically, this study targeted the role of core values within these cultures' development, an area lacking sufficient research (Wagstaff \& Burton-Wylie, 2018). Analysis of experienced championship coaches' responses $(n=5)$ revealed that core values focused on growth and development within sport and beyond, as well as the ways in which group members treat each other. Coaches also revealed that bringing these values off the page required
\end{abstract}


consistent, daily, intentional effort, with values serving as touchstones when actions deviated from them. 


\section{INTRODUCTION}

“I didn't see the future going the right way and I didn't see us being able to re-establish that championship culture" (Fucillo, 2017). San Francisco 49ers Chief Operating Officer Jed York uttered these words in announcing several personnel changes following the 2016 season, including firing head coach Chip Kelly. Just four years removed from an appearance in Super Bowl XLVII, the organization had won two games and would now begin a search for its fourth head coach in four seasons. The organization's struggles and instability betrayed its championship pedigree established decades earlier by Bill Walsh, in which it won five Super Bowl championships in 14 years. Those championship celebrations must have felt like a distant organizational memory as York sat at the dais emphasizing the need to "re-establish the level that we all expect and want for the San Francisco 49ers" (Fucillo, 2017). Responding to reporters' questions, York described missing qualities that needed to return prominently within the organization, such as a shared vision, cohesion, communication, and accountability. York's mention of culture was not casual - he intentionally highlighted the organization's culture 17 times within the media question-and-answer session lasting less than 27 minutes.

Culture has become a trendy buzzword in recent years. Moving beyond its presence in business and other domains, it is has become a part of the common vernacular related to sport. Listening to sports media for mere minutes, one can expect to encounter expression of the concept - either in heaping praise on cultures perceived to be good or in deriding those perceived to be poor. Yet, culture is a multi-dimensional construct, affected by many factors including those related to motivation, communication, and relationships (Schein \& Schein, 2017). These (and other) factors interact to ultimately represent the dynamic and fluid construct of culture. Because of this, culture is a process, rather than a destination (Barney, 1986; Byrtek \& Dickerson, 2013; Frontiera, 2010; Kemmelmeier \& Kühnen, 2012; Kim \& Mauborgne, 2003; 
Schein, 1990; Schein \& Schein, 2017; Smircich, 1983). The type of culture prized by York is not achieved and then left to sustain itself; rather, it is the result of consistent intentional effort to develop and consistent intentional effort to sustain. The lack of consistency and intentionality are among the reasons why cultures may weaken and differentiate themselves from higherachieving competitors (Abdullah et al., 2011; Barrett, 2006; Collins \& Porras, 1996; Jourdain \& Chênevert, 2015).

Publicly, much of the discourse around culture concentrates on the extremes. Professional sports organizations like the San Antonio Spurs are celebrated for their sustained performance excellence and are often lauded for their cultures. Likewise, dynastic collegiate programs like John Wooden's University of California-Los Angeles (UCLA) men's basketball teams, Anson Dorrance's University of North Carolina women's soccer teams, and Geno Auriemma's University of Connecticut (UConn) women's basketball teams have received similar praise for their sustained runs of excellence. At the other end of the spectrum, culture becomes a prominent topic following coaching changes, like that seen recently with the 49ers. But they are far from the only example. The University of Georgia's football program won $74 \%$ of its games during the 15 years in which it was led by head coach Mark Richt, winning at least ten games ten times during that stretch. Yet, the administration felt the program needed a new voice to take the next step and hired Kirby Smart to be their new head coach in December 2015. Shortly after being hired, Smart talked about the need to establish a new culture in Athens, saying, "Not that anything was completely broken here before, but this culture has to be created by [me and my] staff. ... We're going to make sure that every kid understands it's a tough competitive culture" (Weiszer, 2016). Despite some growing pains during his first season, Smart's second season in Athens ended with his team playing in the championship game of the College Football Playoff. 
Similarly, the Golden State Warriors went through a coaching change following the 2010-2011 season. Upon his hiring, new head coach Mark Jackson noted that he was taking over "a job in Golden State with a bad culture, guys that said they wanted to win, but didn't want to win" (Leung, 2015). Jackson helped transform the team into a consistent playoff team. However, despite crediting him with turning the franchise around, the ownership group did not feel it "could be great" under Jackson's leadership, opting to replace him after three seasons. An increased win total and other objective measures of improvement under Jackson notwithstanding, the organization sensed internally that the culture was not strong enough to win an NBA championship (Leung, 2014). The team named Steve Kerr head coach prior to the 2014-2015 season. Kerr is credited with developing a strong culture built upon the core values of joy, mindfulness, compassion, and competition (Thompson, 2016). The strength of the culture is credited with being the backbone of an organization which has since won three NBA championships, made five consecutive appearances in the NBA Finals, and established a new single-season record for wins (73) in a season (Carpenter, 2017).

The moves made by organizations and programs like Georgia football and the Warriors despite their being winning programs - demonstrate that outcome alone is not indicative of an organization's deeper culture. Despite outsiders' ascribing cultural labels based purely on outcomes, it is important for those within the organization to remain vigilant of and attentive to the fluid dynamics of culture, and to continue to guide it in the appropriate direction. However, there is limited empirical information on the cultures of programs that sustain elite performance in sport over time or, more specifically, the processes and mechanisms through which the sustained level of performance is maintained. Therefore, the aim of this study was to examine head coaches' experiences driving sustained elite performance cultures. Within the broader concept of culture, the investigation specifically focused on the core values head coaches deem 
most important for their high-performing cultures and the ways in which these values are taught, lived, and reinforced. 


\section{LITERATURE REVIEW}

While this investigation focused on practices related to sustained elite performance cultures within sport, it was important to note that the research remains limited; the breadth and depth of this literature exists largely in business and organizational domains. Thus, the review of the literature begins in business and organizational contexts, first looking at culture development before illustrating culture's potential as a competitive advantage and, finally, core values' role in these cultures and the leadership of them. From there, these same concepts will be presented within the relevant sport research to highlight the rationale for the current study.

\section{Understanding Culture Development}

Cultural labels are often ascribed based on result: successful teams and organizations (e.g., teams with the best results) are believed to have strong cultures, while those that do not are believed to have weaker cultures. This superficial view of culture undermines its importance and the role it serves within organizations - and speaks to the importance of (and need for) deeper investigation into the topic. Regarded as a seminal voice in the study of organizational culture, Schein's (Schein, 1990; Schein, 2006; Schein, 2010; Schein \& Schein, 2017, p. 6) definition of culture has evolved to be "the accumulated shared learning of a group as it solves its problems of external adaptation and internal integration; which has worked well enough to be considered valid and, therefore, to be taught to new members as the correct way to perceive, think, feel, and behave in relation to those problems." In other words, culture can be thought of as a group's shared understanding of how to navigate internal and external challenges which, having endured these challenges, are worthy of remaining and being passed down to incoming members. 
The shared learning described in Schein's definition of culture refers to a pattern of beliefs, values, and behavioral norms that come to be taken for granted as basic assumptions and eventually drop out of awareness. These components of shared learning are essential elements of Schein's three-level model for culture analysis, which consists of artifacts, espoused beliefs and values, and taken-for-granted underlying assumptions (Schein, 1990; Schein \& Schein, 2017).

The most visible element of any organization's culture is its artifacts. Artifacts include a broad array of categories, ranging from the organization's physical layout, its dress code, the manner in which its people address each other, its smell and feel, or even its emotional intensity. It can also include more permanent aspects such as records, product records, philosophy statements, or annual reports. Despite their visibility and importance, Schein (Schein, 1990; Schein \& Schein, 2017) cautions that artifacts are often difficult to decipher accurately without appropriate organizational knowledge. While investigators or researchers may react in a certain way to artifacts, this reaction may differ from those within the group. As an example, one might observe in comparing businesses that one is more formal than another; however, this does not explain the purpose of the formality or its meaning to the group members. A well-known example from the world of sport, Virginia Tech's football program has passed around a battered lunch pail for more than two decades. To an outsider, it may just look like a dented metal box, but those inside the program recognize it as a treasured symbol of the blue-collar approach and work ethic prized within the program; moreover, it also served to honor the memory of victims following the university's 2007 school shooting (Schlabach, 2007). Without the story and context of the artifact, its meaning might be misunderstood - if not lost completely. 
The next level upon which culture can be analyzed is through its espoused and documented values, norms, ideologies, charters, and philosophies (Schein, 1990). At this level of culture analysis, researchers aim to discover why phenomena happen the way they do. Schein (Schein, 1990; Schein \& Schein, 2017) notes that interviews, questionnaires, and surveys are often used to identify this level of culture; however, they pre-judge the cultural dimensions to be studied. For this reason, the author recommends a deeper look into the culture through intensive observation, more focused questions, or involving key members of the group in intensive self-analysis to get at the more deeply-held assumptions which determine perceptions, thought processes, feelings, and behaviors. Once the assumptions are understood, one can more easily decipher the implicit meanings of various observed behaviors and artifacts.

While these levels are described separately for the sake of explanation, Schein (Schein, 1990; Schein \& Schein, 2017) described a connection between these levels, feeding each other to strengthen the culture. Deeply held assumptions, he describes, often begin as values which, as they persist over time, gradually begin to be taken for granted and take on the character of assumptions. At that point, they are no longer questioned or subject to discussion - they are simply the way things are done around here. Rituals have been proposed as one mechanism for this connection. Rituals are actions full of symbolism with which stakeholders express acceptance and approval of the symbolized values (Sosis \& Ruffle, 2004). Likewise, rituals utilize artifacts (such as dress code or which members have priority in given settings) to establish a behavioral or emotional tone that, over time, is passed down and eventually taken for granted (Sueldo \& Streimikiene, 2016). Utilizing the Virginia Tech example above, the artifact represents the cultural values and assumptions about hard work. The ritual of passing it to teammates is part of the mechanism through which they endure, are honored, and are transferred to future members. 


\section{Culture as a Competitive Advantage?}

Beyond merely being a component of long-term success, previous research has argued that culture could even be a source of competitive advantage for organizations (Barney, 1986; Schneider \& Bowen, 1993). Based on earlier work from strategists and economists (Hirshleifer, 1980; Porter, 1980), Barney (1986) identified three conditions that must be satisfied to obtain the advantage: the culture must be valuable, rare, and imperfectly imitable. A valuable culture was described as one that carried a positive economic value for the firm. A rare culture, meanwhile, was one that existed in only a small number of firms. And, finally, an imperfectly imitable culture was characterized as being hard for current or former members to describe or explain within efforts to recreate the culture elsewhere. While important, it is intuitive that a business that does not produce value (e.g., profit) will eventually cease to exist in its current form (if at all). Likewise, if the cultural elements are commonplace throughout the industry, then the culture is not producing any type of advantage for the organization. Therefore, the third quality, that the culture is imperfectly imitable, represents a critical element of its potential to be a source of competitive advantage. One possible explanation for the difficulty in imitating successful cultures may lie in the differences in shared experiences and learning. In this case, artifacts would lack the shared meaning and history that made them powerful in the original culture (Barney, 1986; Clark 1972; Smircich, 1983). Moreover, rival organizations frequently poach key people from successful organizations in an attempt to replicate the culture's success. Given the specific elements evident within the original organization, these efforts often become attempts to imitate the successful culture rather than create a new successful one. Barney (1986) argued that, despite other organizations' attempts to mimic successful cultures, imitation cannot be considered a competitive advantage. At best, he asserted, imitation only serves to make other cultures less rare, bringing them back to a more 
normative place. Likewise, personal values held by individuals within the organization (and their alignment with the organization's) cannot be imitated (Schneider \& Bowen, 1993).

At a broad level, organizational culture has been connected with various organizational outcomes - across multiple nations and across multiple domains. For example, recent studies have demonstrated that organizational culture had a significant and positive effect on employee performance among Indonesian bank employees (Sihombing et al., 2018); culture had a similar effect on talent attraction and retention, as well as employee motivation, satisfaction, and commitment in both automotive supply chain employees in the southwestern United States and telecommunications employees in Cyprus (Kontoghiorghes, 2016). Additionally, an artifact of culture, communication, was shown as a partial mediator between organizational culture and organizational effectiveness within the education sector in India (Gochhayat et al., 2017). Meanwhile, Denison and Mishra (1995) found that culture was a strong predictor of quality, employee satisfaction, and overall performance in industrial organizations in the midwestern United States. Sørensen (2002) found that firms with strong cultures performed better and exhibited more reliable performances than those firms with weaker cultures under stable conditions. Moreover, the author also found that, this cultural effect was not diminished under more volatile conditions, suggesting that firms with stronger cultures may be better able to weather short periods of volatility without performance decrement.

Perhaps relatedly, organizational culture has also been associated with sustained and long-lasting organizational success. As successful organizations develop appropriate responses to their internal structures and external environments, they go through a natural evolution and adapt (Denison \& Mishra, 1995; Schein \& Schein, 2017). Through the values they emphasize and the behaviors they reinforce, leaders play a vital role in facilitating this adaptivity within their organizations (Kotter, 1998). While the organization's deeply held assumptions remain, the 
strategies for interacting with and confronting these challenges may adapt (Collins \& Porras, 1996). This adaptability was found to be a key moderator in the relationship between culture and financial performance within a sample of US-based technology companies (Chatman et al., 2014). Furthermore, Costanza and colleagues (2016) looked at companies' survival rates across multiple domains (including some from manufacturing, retail, insurance, and utilities, among others), identifying that firms which rated highly in both values and actions related to change were most likely to survive the longest. These findings suggested that, beyond the organization's values toward potential change, it must also be willing to take the necessary steps to make and sustain the changes in response to its environment.

\section{Core Values Driving Action}

The importance of core values is made clear in the way they are described in the literature. Just a few of the ways core values are described includes their role as "glue" between employees (Barchiesi \& La Bella, 2014), an organizational beacon (Margulies \& Raia, 1988), drivers of behavior (Abreu et al., 2009; Sueldo \& Streimikiene, 2016), drivers of individual and organizational performance (Oh et al., 2018), a component of intellectual capital (Edvinsson \& Malone, 1997) and even the defining characteristics of a culture (Lencioni, 2002; Williams, 2002). Indeed, core values help influence which issues achieve salience within the organization (Pant \& Lachman, 1998). Oh and colleagues (2018) identified three key features of core values in the literature, specifically that 1 ) they are based on organizational culture that builds cohesion within the organization, 2) they are practical principles guiding employees' behavior and decision-making, and 3) they are shared beliefs among the organization's employees that relate to organizational goals and objectives. 
While core values can be these powerful and galvanizing forces within organizations, they can just as easily be empty words within documents that rarely get referenced. Jollands, Akroyd, and Sawabe (2015) found that a lack of clarity around a core value's definition, and its accompanying process of implementation, led to the value's stagnation within the organization and, ultimately, its being abandoned. In contrast, values-based actions (VBA), or acting in accordance with the values, is one way to combat values becoming latent or inert. Oh and colleagues (2018) defined VBA (in their words, practicing core values) as the degree of applying the organizational core values in the daily tasks at work and reflection of these values in employees' attitudes. Acting in accordance with values is important in many ways, including organizational development (Viinamäki, 2009) and corporate image (Barchiesi \& La Bella, 2014); in fact, utilizing core values to guide decision-making has been proposed to be a distinguishing feature among long-lasting successful companies (Collins \& Porras, 1996; Sufi \& Lyons, 2003). As an example, Volvo keeps its values relevant via strategically integrating its core values with its mission statement and making them future-oriented - and, thus, never satisfied (Urde, 2003). If the values were static, they would only be descriptions and it would be easy for them to lose their importance. By making them future-oriented, the values continue to represent something to strive for and a guiding light for which future behaviors can be directed.

As mentioned, each of the three levels of Schein's model of cultural analysis are connected. As groups act, they get feedback on their progress toward accomplishing their purpose. If a group succeeds - and continues to succeed - then the beliefs, values, and behavior patterns that launched the group will be taken for granted as the way to continue. With time and continued success, those beliefs and values become part of the group's identity and will be taught to newcomers as this is who we are, and this is what we do. Even if the values and beliefs were debated at first, they become non-negotiable assumptions that new members are 
expected to adopt when they join the group (Schein \& Schein, 2017). In this way, as values and beliefs are reinforced, stakeholders come to perceive the importance of acting in accordance with values even if (at first) they were not personal values.

Urde (2003) demonstrated what examples of VBAs looked like at Volvo. The company's core values of safety, quality, and concern for the environment are clearly represented in the company's mission and vision, and even its brand statement:

Based on customer-perceived quality and achievements, Volvo will distinctly, decisively, and consistently sustain and develop its brand position as a recognized leader in safety and be ranked as a leader in terms of environmental care among the world's top producers of automotive and transport products, equipment and systems (p. 1025).

These core values are emphasized beyond the corporate level and are also visible at the product level. Volvo's top point of emphasis, safety, can be understood through the company's track record of being at the forefront of automotive safety innovations for decades - including seatbelts, collision protection, and airbags throughout their vehicles. Further, these core values are reflected in the way Volvo positions itself in the market and promotes itself to customers. Indeed, this integration has actually served as a source of competitive advantage for the company as safety has come to be associated with the brand's identity (Urde, 2003). As Barney (1986) noted, while other companies may imitate the innovations, the value may not to be as deeply integrated into other companies (or as high a priority) as it is with Volvo, making it difficult to imitate within other organizations.

\section{Core Values Driving Leadership}

Both employees and those in leadership positions at Volvo are encouraged to act in accordance with core values; a well-known story within Volvo's culture describes a former CEO's 
directly and personally contacting the media in the 1990's to express his personal and his company's engagement in environmental issues, one of Volvo's core values (Urde, 2003). Although many factors influence culture, leaders are one of the primary influences. Leaders influence culture through their strategies and practices, values, leadership style, and example (Steers \& Shim, 2013). Beyond developing a climate in which VBAs are emphasized, leaders can send a powerful message to their employees about the importance of these behaviors by acting in accordance with the values themselves (Kottke \& Pelletier, 2013; Warrick, 2017). Leaders' behaviors and actions, demonstrated values, and personal willingness to change send a strong message (Gehman et al., 2013). Through their words and actions, leaders convey to their employees which behaviors and beliefs are valued and which are devalued - a practice known as values-based leadership (VBL); VBL is believed to be effective in organizations, both as a guide for actions as well as through providing a path for adapting and responding to the environment (Sull, 2010). Just as with VBAs, a connection between words and actions - and accountability to it - is necessary for this to be effective; empty value statements can have a detrimental effect on, and even undermine, leadership (Ferguson \& Milliman, 2008; Lencioni, 2002). Myriad corporate scandals in the early years of the twenty-first century (including those at Enron, Adelphia, and WorldCom) revealed this disconnect between actions and words as companies' and leaders' decisions deviated from their foundation. More recently, Wells Fargo provided a high-profile illustration. Regardless of other stated core values, as leadership emphasized sales, many within the company became more aggressive to meet sales targets. Over a five-year period, more than two million accounts were opened without customers' authorization by employees willing to act unethically to meet the sales goals and earn related incentives (Warrick, 2017). These behaviors led to severe consequences, as the company faced immediate 
financial consequences, went through a change in leadership, and continues to deal with the public relations damage caused by the practices.

In the wake of these scandals, values-based leadership has gained increased attention and has even seen its definition evolve into more broadly referring to a congruence between the leader's values and the organization's values (Fernandez \& Hogan, 2002). In a review of the literature, Copeland (2014) identified the three most emphasized constructs in VBL research: ethical leadership, authentic leadership, and authentic transformational leadership. As a leadership style, ethical leadership shares many of the same characteristics of authentic and transformational forms, such as altruism, ethical decision-making, integrity, and role modeling; a major distinction is its emphasis on moral management and a focus on others (Brown \& Treviño, 2006). Because of these similarities, and the fact that, while important, ethics are not a specific emphasis of this investigation, the current investigation will shift its focus to other specific leadership types related to VBL.

\section{Transformational Leadership}

Burns (1978) was credited with introducing the concepts of transactional and transformational leadership, definitions of which were enhanced by Bass (1985). Transactional leadership refers to an exchange relationship between leaders and followers, allowing leaders to meet their own self-interests. This can take the form of contingent reward (in which the leader provides an explanation of what needs to occur for the follower to be rewarded), active management-by-exception (in which leaders monitor and take corrective action if the follower fails to meet standards), or passive leadership (in which the leader waits for problems to arise before taking corrective action, or even avoids taking any action). In contrast, transformational leadership refers to the leader moving beyond immediate self-interests through idealized 
influence (charisma), inspiration, intellectual stimulation, or individualized consideration. Leaders display idealized influence and inspirational leadership through envisioning a desirable future, providing a path to achieve it, setting an example, setting high standards of performance, and demonstrating determination and confidence. Intellectual stimulation is displayed when the leader helps followers become more innovative and creative. Finally, individualized considerations are displayed when leaders attend to the developmental needs of the followers, and support and coach this development, providing opportunities for growth (Bass, 1999).

Utilization of these transformational leadership behaviors can profoundly impact the organization. Sarros, Gray, and Densten (2002) found that leadership was a far better predictor of culture than culture was of leadership within a sample of Australian private sector business managers. With a similar sample, Sarros, Cooper, and Santora (2008) found that transformational leadership accounted for $24 \%$ of the variance in organizational culture. Meanwhile, transformational leadership has also shown to be a significant predictor of innovation climate, as well as have an indirect effect (fully mediated by innovation climate) on employee creativity among a sample of hotel employees in India (Jaiswal \& Dhar, 2015). Further, Ross and Gray (2006) investigated transformational leadership in a sample of Canadian elementary school districts, finding that the teachers' perception of their principals' leadership was a significant predictor of collective teacher efficacy within the school, as well as the teachers' commitments to the school's mission and the professional community.

Sarros and colleagues (2002) found that the Australian managers felt they utilized both transformational concepts in their leadership (inspirational motivation, intellectual stimulation, idealized behaviors), as well as elements of transactional leadership (contingent reward). Thus, perhaps it is worth considering the depth of relationships that leaders seek to create, as 
opposed to merely considering the behaviors; in other words, it may be a combination of "what you say" and "how you say it." To that end, Schein and Schein (2017, p.100-102) describe four levels of relationships in society. At the bottom level (Level -1), there is exploitation, no relationship or a negative relationship. Examples of this type of relationship would be prisoners, sometimes very old or very emotionally ill people, or "marks" for criminals. While relationships are sometimes formed at this level, there is no expected level of trust or openness. The next level (Level 1) is categorized by acknowledgement, civility, and transactional role relations. Examples of this type of relationship include strangers on the street, seatmates on a plane, or service people whose help we need and whose role definition requires a professional distance. At this level of relationship, the people do not know each other, but treat each other with a baseline level of respect and trust that the other person will do no harm. The third level (Level 2 ), is characterized by the recognition of the other person as unique, and the establishment of working relationships. Examples of this level might include casual friendships or coworkers. This level is characterized by a deeper level of trust and openness in terms of honoring promises and commitments, agreeing not to harm or undermine the other person, and agreeing not to lie or withhold relevant task information. Finally, the fourth level (Level 3) is characterized by close friendships, love, and intimacy. Examples at this level include relationships where strong positive emotions are involved. At this level, trust goes beyond what was expressed in Level 2 in that people not only agree not to harm each other, but they actively support each other and are more open.

The authors (Schein \& Schein, 2017) suggested that a Level 3 relationship may be undesirable in professional situations; it could be argued, though, that certain professions (such as coaching) which strive to develop and educate people on a personal level as much as on a "professional" level could be exceptions. Regardless, through the establishment of deeper 
relationships, behaviors potentially aligning with transactional coaching may not be perceived as the entire foundation of the relationship, but merely a component of it, which may alter the actions' perceived meaning. Indeed, Yukl (1999) advocates that the specific outcomes of transformational leadership may be highly dependent on the situational context.

\section{Authentic Leadership}

Authentic leadership is hardly a new concept, but it gained increased attention in the literature and from practitioners following the corporate scandals of the early 2000's. Authentic leadership is characterized by leaders who have the ability to acknowledge their thoughts, emotions, needs, wants, preferences, and beliefs, and act consistently with those inner feelings and beliefs (Gardner et al., 2005). Harter, Schmidt, and Hayes (2002) asserted that one's authenticity can be viewed on a spectrum, and that, as leaders are better able to understand and articulate who they are and what they believe, they can become more authentic - both as people and leaders. Authentic leaders - and authentic leadership - have been described as one of the key factors for reinforcing organizational core values (Jeffery \& John, 2008). Specifically, authentic leadership was found to have a significant positive effect on work engagement, as well as values-based actions among a sample of Korean corporate leaders (Oh et al., 2018). Authentic leadership was also positively associated with work engagement and dedication (Wong et al., 2010), as well as perceptions of one's overall person-job match (Bamford et al., 2013) within the nursing field.

While not directly a component of authentic leadership, several authors (Ab Hamid, 2015; Abdullah et al., 2012; Abreu et al., 2009; Amis et al., 2002; O’Reilly \& Chatman, 1996; Ogbonna \& Harris, 2000; Posner \& Schmidt, 1993; Schneider \& Bowen, 1993; Warrick, 2017) have described the importance - and potential effects - of the congruence or alignment (or lack 
thereof) between employees' values and those of the organization; in other words, the literature has described the degree to which organizational values are perceived as being authentic. From an organizational perspective, former CEO of Levi Strauss \& Company Robert Haas, has argued that alignment between organizational values and personal values is the key driver of corporate success (Howard, 1990). This value congruence has shown to be predictive of job satisfaction and eventual organizational turnover (O'Reilly et al., 1991). Beyond employees, similar findings have also been reported among managers. Posner and Schmidt (1993) asked American managers to self-rate their personal and organizational value congruence. The authors found that high congruence was positively associated with qualities like organizational commitment, success, credibility, as well as various dimensions of ethics. Interestingly, the authors also found that those managers with clear personal values, but lacking clarity of organizational values responded more like the high congruence group; meanwhile, those clear on organizational values but with unclear personal values responded more like the lowcongruence managers. However, Finegan (2000) found that employees' perception of organizational values was a better predictor of commitment than either the employees' personal values or their congruence with the organization's. Despite these conflicting findings, both address the importance of the need for clearly-developed and clearly-defined values to allow for aligned actions.

\section{Values as a Control Mechanism?}

Related to this concept, as well, is the notion that core values may serve as a control mechanism for the organization (Amis, et al., 2002; Janićijević, 2017; Jollands et al., 2015; Lachman et al., 1994; Simons, 1994). Pant and Lachman (1998) described values as being core values when their influence on what people do supersedes that of most other values in the value system. Schein and Schein (2017) described how founding leaders of organizations impose 
structure, systems, and processes within the organization and, if the organization is successful, they become shared and part of the culture. These shared assumptions perpetuate within the culture as they are taught to new members, which, in so doing, manipulate members into perceiving, thinking, and feeling certain ways (Van Maanen \& Kunda, 1989; Kunda, 1992, 2006). Likewise, feedback and reward systems motivate members and reinforce their behavior (Latham \& Pinder, 2005). Certainly, these findings offer support for the idea of core values acting as a control mechanism for the culture, but that does not necessarily mean the values are constricting. Tushman and O'Reilly (1997) described that clear values act as important decisionmaking guides yet can do so without the need for formal rules or policies which might constrict autonomy. Likewise, O'Reilly and Chatman (1996) suggested that the alignment of personal and organizational values enabled commitment to a set of meaningful values, providing meaning and increasing intrinsic motivation and effort.

\section{Strategy for Implementing Values Within the Culture}

An important question remains, though: if VBL is important, then how specifically can it be utilized to bring core values to life within a culture? From a review of the literature, Byrtek and Dickerson (2013) identified - and then subsequently tested - an eight-step model for actualizing core values. The first two of the eight steps, respectively, involved the leadership's articulation of the core value(s) and defining it through the establishment of a common meaning and role expectations. The third step included the leadership's active modeling of the core values. The fourth step involved the leaders' engagement and empowerment of those underneath them. Ensuring that systems were aligned was the fifth stage, which included things like eliminating obstacles, challenging current practices, developing mechanisms that support the values, and integrating the values in human resource management practices. The sixth step related to leaders' practices for reinforcing the values. Lastly, the final two stages, respectively, 
involved the development of measures to assess progress in actualizing the values, as well as continually measuring and monitoring its actualization.

The authors subsequently tested the model within a case study design that included a pair of universities. The authors found that when it came to the implementation of a new value within the organization, the steps did not capture the entire process. First, the authors noted, there needed to be an initial first step added to the model in which the leader assesses current and historical cultural contexts. Whether incorporating additional values into a culture - or drastically changing them, as in the case of a leadership transition - it is important for leaders to understand the context in which the old values system existed. While this may seem like an implied part of articulating and defining new value(s), Byrtek's and Dickerson's (2013) findings suggested that the effort to understand context warranted its own stage within the model and made it more representative of the process observed within their study. Moreover, the authors added that, while introducing this process in a series of steps for the sake of presentation, there was often overlap and the process was not as linear as the model makes it appear

The importance of having a strategy has been highlighted in the literature (Amis et al., 2002; Pant \& Lachman, 1998; Urde, 2003), and findings from several studies align with these proposed steps. Taken as a whole, Van Rekom, van Riel, and Wierenga (2006) emphasized the implementation of core values at all levels of the organization facilitates management's ability to develop strategies and improve coordination and morale throughout the organization. Thus, being clear and specific with the values, as well as communicating and reinforcing them, is vital for their gaining traction within the organization. Likewise, Thyssen (2009) emphasized the need for common values definitions and classifying values in terms of their expected roles in decisionmaking. And, in conjunction with the final step in the process, Barrett (2006) advocates for extensive monitoring of values and related behaviors. 


\section{Organizational Culture in Sport}

Organizational culture in sport has gained increased attention in the literature in recent years. However, while research has highlighted its importance (Fletcher \& Arnold, 2011; Weese, 1996), a clear understanding of the construct within sport is, to date, elusive. Culture is often ascribed based on result (e.g., winning teams are presumed to have strong cultures), but this ignores a myriad of contextual factors such as talent discrepancies, imbalanced schedules, financial opportunities or constraints, among others, that distinguish winning and culture. Other contextual factors must be considered when analyzing culture in all domains (Schein \& Schein, 2017), but especially in sport. For example, the University of Alabama football program had massive turnover to its roster and coaching staff heading into the 2018 season. Head coach Nick Saban's staff had six new assistant coaches from the previous year's staff, and only one assistant coach remained in the same role as in the previous season (Glier, 2018). Without context, this type of turnover could raise a number of red flags; that several of the coaches had gone on to earn head coaching positions or promotions elsewhere, yet the program continued its elite performance, is the true testament to the culture within that program and Saban's leadership of it. Culture has been shown to have a strong relationship with organizational effectiveness (Weese, 1996).

Barney's (1986) assertion of culture as a potential competitive advantage may provide insight into the recent sustained run of excellence by the San Antonio Spurs over the last two decades. Barney described a valuable culture as one that created a positive economic value for the firm. However, it is important to understand the context of which elements determine organizational effectiveness (Abdullah et al., 2012) - some of which are unique within sport. The Spurs participate within a larger sports league (the National Basketball Association, or NBA) that spreads league-wide revenues (such as media and advertising rights) amongst all its members; 
so, organizations are not solely dependent on their individual earning capabilities to generate revenue. Moreover, "winning" in business is largely a function of profit maximization, whereas in sport financial success is not always correlated with on-field results. As examples, the Florida Marlins performed well enough on the field to win the 1997 World Series yet were immediately dismantled due to claims of lost revenue (Zimbalist, 1998); meanwhile, the Los Angeles Clippers under former owner Donald Sterling were "a team that historically had low revenue and low attendance and made money in spite of that" (Isadore, 2014). Despite turning a profit, no one would confuse the Clippers with being an exemplary organization; between myriad accusations that ultimately led to Sterling's exit from the franchise and a lifetime ban from the NBA (Moore \& Avila, 2014), the organization won a mere $37 \%$ of its games during the course of his 33 -year tenure as owner. Perhaps, applied to sport, Barney's condition of value may reflect some combination of the two - earning both wins on the field and revenue off it.

While the concept of a valuable culture (when applied to sport) may still require further elucidation, the other two conditions' (that cultures are rare and imperfectly imitable) relevance seems clear; this is where cultures like the Spurs illustrate their ability to be a competitive advantage. Year after year, rival organizations attempt to understand what makes their cultures distinct and find ways to replicate them. A brilliant illustration of this was highlighted by former Spurs assistant coach and current Charlotte Hornets head coach James Borrego's description about how, in recent years, several of the Spurs' assistant coaches were all competing against each other for available head coaching opportunities with other organizations (Wojnarowski, 2018). Meanwhile, none of the former coaches have been able to replicate (at least to date) the Spurs' successes with their new organizations. It is worth noting, as a testament to both the difficulty in replicating this type of cultures, as well as its rarity, that the Spurs employed a generational talent at the heart of their dynastic run. Yet, while Tim Duncan's recent election to 
the Naismith Basketball Hall of Fame is indicative of his talent, it is also reflective of his own strong leadership qualities, effective communication, and a mandate for instruction and feedback in alignment with the organizational culture in which he performed.

Comparing the business and sport domains directly, Weinberg and McDermott (2002) found large agreement between the factors related to organizational success. Looking at elements of leadership, cohesion, and communication, the authors determined that the major difference across domains was simply the degree to which certain elements were emphasized, rather than there being separate factors. Both groups, composed of midwestern business managers and collegiate and high school coaches and athletic directors, emphasized elements of leadership, cohesion, and communication. From a leadership standpoint, coaches emphasized the importance of consistency, while business leaders most frequently described honesty as an important leader characteristic. While business leaders emphasized the importance of being a good listener as an important interpersonal skill, coaches highlighted the importance of being able to interact with a variety of people. Both groups emphasized the importance of democratic styles of leadership, yet both also recognized there were times when autocratic decision-making was necessary. Leaders of both domains advocated for cohesion; despite more discussion of its social elements, leaders across both domains described the importance of task elements such as goal setting and role acceptance, with the development of a shared vision being viewed as an essential element for the development of cohesion.

Regarding communication, both leader groups agreed that communication should be concise, clear, frequent, and honest. However, while sport leaders tended to advocate more for positive reinforcement and feedback than business leaders, business leaders noted the importance of listening skills such as reflective listening, paraphrasing, and giving consistent nonverbal cues. Similarly, Smith and Shilbury (2004) found overlap between sport and non-sport 
organizations. Their sample of Australian national and state sport organizations utilized similar artifacts to those seen more generally within organizations (e.g., rituals, symbols, history and tradition), with the difference being in their specific manifestations - even when comparing their role within the sample of organizations used for their study. Further, artifacts' meaning even within a single organization - can vary without clear and specific explanation, as Mills and Hoeber (2013) found within a figure skating club.

Additionally, Jones (2002) found striking similarities in the ways in which the pursuit of excellence was mirrored across both domains: organizational issues, stress, leadership, highperforming teams, and one-on-one coaching/consulting. Organizational issues referred to the structures within the organization that can support or constrain performance, including the availability of resources, communication, and strategy. The second factor, stress, was a recognition of stress's effect on performance and described the utilization of coping strategies focused on emotion-focused coping, reappraisal, and (where possible) eliminating or minimizing the stressor. The third area, leadership, emphasized transformational leadership behaviors. The fourth dimension, high-performing teams, reflected qualities like motivation, respect, responsibility, and communication among its key variables across both domains. The authors also described team-building strategies organizations could employ to foster cohesion among their members. The final level, one-on-one coaching/consulting, refers to the need for specific and timely feedback to foster efficacy and motivation.

\section{Values Driving Actions and Leadership in Sport}

Upon his arrival with the San Francisco 49ers, Bill Walsh recognized the critical role values - and leading through them - would play in building his desired culture. "I came to the San Francisco 49ers with a specific goal - to implement what I call the Standard of Performance. 
It was a way of doing things, a leadership philosophy, that has as much to do with core values, principles, and ideals as with blocking, tackling, and passing; more to do with the mental than the physical" (Walsh, 2010, p. xxiv). Clearly, Walsh recognized that he was going to need to coach technique and the fundamentals of the game. But, that alone was not going to build the long-lasting culture he strived to develop. The foundation of that culture would be the beliefs and core values behind what was being taught - and how it was being taught. Indeed, Trail and Chelladurai (2002) advocated for leaders aligning their actions with values following their investigation of a midwestern Division I athletic department. Likewise, leaders viewed as being prototypical of culture were rated as more effective (Aicher \& Cunningham, 2011).

From an administrative standpoint, Cooper, Weight, and Pierce (2014) found that collegiate athletic administrators from a national sample of Division I athletic departments viewed values of ethics, integrity, honesty, sportsmanship, teamwork, and responsibility as having the highest priority within their athletic departments. Meanwhile, Hutchinson and Bennett (2012) found a lack of congruence between espoused core values and those actually implemented within a university athletic department, including some identical values to those investigated by Cooper and colleagues. Various internal and external stakeholders identified that certain values (e.g., excellence) were present only via the surrogate of winning, while others were for public relations purposes without associated action; the incongruence was believed to be related to a lack of strong leadership (at both the athletic department and university levels) to model and help mold and integrate these values within the department. This lack of consistency also connected with an inconsistent view of the department's brand image - and speaks to the critical importance of leaders' holding themselves and those under them accountable to the values.

\section{Transformational leadership in sport}


Beyond being a leadership style identified as important among coaches (Vallée \& Bloom, 2005), transformational leadership has also been associated with positive outcomes in sport. Within a sample of university campus recreation departments, leaders scoring high on transformational leadership were found to have significantly stronger and more positive cultures than leaders scoring low on transformational leadership (Weese, 1995). At an organizational level, Kent and Chelladurai (2001) described a cascading effect for the effect of transformational leadership within a study of a collegiate athletic department. Mid-level managers (in this case, associate athletic directors and department directors) were found to emulate the transformational leadership of the athletic director in communicating with those serving under them, which may be indicative of the inspiring effect transformational leaders have on those working under them.

Transformational leadership qualities have also been associated with performance. Bormann and Rowold (2016) found that leaders rated higher in Articulating a Vision and Providing Individualized Support were positively and significantly related to player performance in a sample of German professional basketball players. Perhaps related to the inspiring nature of transformational leadership, intrinsic motivation has been found to mediate the relationship between transformational coaching and coaches' ratings of athlete performance in Canadian university athletes across multiple sports (Charbonneau et al., 2001). Specifically, Individual Considerations and Intellectual Stimulation were significantly correlated with intrinsic motivation. Moreover, transformational coaching behaviors have also been associated with increased perceptions of effective coaching behaviors, feelings of satisfaction with the coach, and the exertion of extra effort (Rowold, 2006), as well as enhanced commitment to the organization (Kent \& Chelladurai, 2001). 
Previous research has demonstrated the benefits of enhanced team cohesion on efficacy and performance across multiple sports (Carron et al., 2002; Paskevich, et al., 1999; Price \& Weiss, 2011). Callow, Smith, Hardy, Arthur, and Hardy (2009) discovered that transformational leadership behaviors were predictive of both social and task dimensions of cohesion. In a sample of ultimate frisbee players, the authors found that Fostering Acceptance of Group Goals and Promoting Teamwork predicted social cohesion. Beyond social aspects, task cohesion was predicted by Fostering Acceptance of Group Goals and Promoting Teamwork, High Performance Expectations, and Individual Considerations (Callow et al., 2009; Smith et al., 2013). Notably, when the aforementioned sample of ultimate frisbee players was split on ability, the authors discovered that Individual Considerations was a predictor of task cohesion for the higher-performing group, but not for the lower-performing group. One possible explanation for this finding was that individual considerations become more important as one progresses to more elite levels of experience and ability, compared to the more gross adjustments that may happen at earlier stages of skill development. And, the deeper relationships seen in transformational leadership may contribute to understanding these specific needs; this would support individualizing suggestions for improvement, and even being part of the connection between these considerations and the enhanced task cohesion. Meanwhile, a vital component of task cohesion, participants' willingness to sacrifice their own self-interest for the betterment of the group, may also be related to transformational leadership. Cronin, Arthur, Hardy, and Callow (2015) demonstrated that a concept termed inside sacrifice, the sacrifices athletes make in practice and competition, mediated the relationship between five specific dimensions of transformational coaching (Individual Consideration, Fostering Acceptance of Group Goals, High Performance Expectations, Appropriate Role Model, and Inspirational Motivation) and task cohesion. 
Additionally, communication represents a potential mediator between transformational leadership and task cohesion (Smith et al., 2013). The authors observed that intrateam communication mediated the relationship between selected transformational leadership behaviors and task cohesion. It is important to note that for the ultimate frisbee samples in this study, as well as by Callow and colleagues (2009), organization, strategy, and training were organized by the team captain rather than a distinct coach. The lack of coach may have intensified the importance of intrateam communication, yet it also obscured understanding of the potential role of this communication in a more traditional team setting with a coach.

\section{Autonomy-supportive leadership in sport}

Basic Psychological Needs Theory posits that people must satisfy their basic psychological needs of competence, autonomy, and relatedness to experience positive outcomes, such as psychological well-being, optimal development, and autonomous forms of motivation (Deci \& Ryan, 2000; Ryan \& Deci 2008). Thus, autonomy-supportive coaching behaviors - those that provide student-athletes with a sense of agency - may provide (at least a degree of) counterbalance to the perception of core values as organizational controls. Indeed, autonomy-supportive coaching behaviors have also been associated with increased selfdetermined motivation across a range of sports including gymnastics (Gagne, 2003), soccer (Hollembeak \& Amorose, 2005; Weston et al., 2011), and judo (Gillet et al., 2010). Specifically, Hollembeak and Amorose (2005) found that an autocratic coaching style, one rigid in its decision-making and demanding obedience to those decisions, had a negative relationship with psychological needs (specifically relatedness and autonomy) and intrinsic motivation. Meanwhile, each of those same psychological elements was positively related to a democratic coaching style, encouraging of athletes' input. 
Moreover, these behaviors may have an influence on commitment and performance.

The degree to which truly intrinsic motivation occurs within elite sport can be debated, but even if the motivation is externally-driven, participation and commitment can still be self-determined. In a sample of elite swimmers, those perceiving autonomy support from their coaches demonstrated greater persistence to continue than those perceiving their coaches to be controlling (Pelletier et al., 2001). More specifically, along the continuum of motivations and regulations within Self Determination Theory, the authors found that athletes displaying amotivation or externally-regulated motivation withdrew most rapidly; introjected regulation predicted short-term, but not long-term, persistence; and those displaying identified regulation or intrinsic motivation exhibited the lowest dropout rates. Autonomy-supportive coaching behaviors have also demonstrated a positive relationship with athletic performance, including among soccer players (Chen et al., 2013) and judokas (Gillet et al., 2010). Specifically, Gillet and colleagues (2010) found that judokas' perceptions of autonomy support indirectly influenced subsequent performance through contextual and situational motivations. In other words, the coaches' autonomy support predicted the athletes' motivation toward judo (contextual motivation), which in turn predicted their motivation specifically for the upcoming competition (situational motivation), which ultimately predicted their performance in the competition.

\section{Developing culture in sport}

While culture is an important part of consistent organizational success, it is not a onesize-fits-all construct. With its reliance on shared learning, culture is necessarily a group effort. Therefore, culture development must allow for individual styles (Fletcher \& Wagstaff, 2009; MacPherson \& Howard, 2011; Schroeder, 2010). A large share of the literature on culture development in sport has emphasized culture change, which is often accompanied by changes in leadership. Changes in leadership, however, do not always result in positive changes (Andersen, 
2011). Indeed, Pain and Harwood $(2007,2008)$ found that various cultural elements were perceived to have both positive and negative effects on performance among the England youth soccer team athletes. Stated parsimoniously, Cruickshank, Collins, and Minten (2014, 2015) described enduring culture change in both Olympic and professional sport as a two-step process. The first step, initial evaluation, planning, and impact, involved leaders establishing the focus and content of the culture. This was paired with a second phase, management of a holistic, integrated, and social system, in which internal and external stakeholders are managed.

Frontiera (2010) provided insight into successful culture change processes in American professional sport - based on comparisons of the teams' winning percentages prior to and following the change - gaining rare access to key decision-makers in the NBA, National Football League, and Major League Baseball. Following qualitative interviews with the owners and general managers, the author described a five-step process as these organizations worked to turn around losing cultures. Similar to the findings of Byrtek and Dickerson (2013) who emphasized the importance of identifying the current and historical cultural contexts, the author identified Symptoms of a Dysfunctional Culture as the first step toward a cultural turnaround. In this case, the decision-makers identified a negative environment (which included poor physical conditions such as inadequate facilities, an absence of values, and even the presence of values inconsistent with success) and an environment in which losing had become a habit (which included reduced effort, accountability, and communication).

The next three steps, My Way, Walk the Talk, and Embedding New Culture reflected the ways in which the leader's vision for the new culture would be taught and reinforced. Initially, the leaders introduced their respective organizational visions, as well as their values - many of which were related to the leaders' beliefs about how people should treat each other (Frontiera, 2010). Moreover, certain personnel were changed in this early phase, intentional efforts were 
implemented to grow and develop personnel, and clear and honest communication was implemented initially. Meanwhile, the decision makers also spoke about the importance of culture being reinforced every day, the importance of persisting in the face of obstacles, and the importance of artifacts in reinforcing the new culture's values. Specifically, the leaders also described the importance of values-driven behaviors as a way to respond to critical events to show that new values existed within the organization and that old behaviors would not be tolerated. These reinforcers took root within the organizations as the leaders identified small victories to support new values and vision within the organization, and took advantage of potential cultural turning points when they arose. The final step in the cultural turnaround (Our Way) was evident as the leader's organizational vision and values spread throughout the organization. This shift became evident in the ways people within the organization acted with each other and in the face of difficult decisions - opting to act in accordance with values. Moreover, those within the organization were described as making better decisions and thinking independently and innovatively within the blueprint of the organization's vision and values. Despite differences in semantics or parsimony in the organization of steps, these findings share considerable overlap with seminal literature on group formation dynamics (Tuckman, 1965).

At the college level, Schroeder (2010) explored the idea of culture as a change agent in organizational turnaround, while also aiming to identify specific leader behaviors that facilitated the culture change. In his study, the author interviewed ten collegiate head coaches across multiple sports (basketball, football, softball, and volleyball) responsible for turning around unsuccessful programs. Despite using different nomenclature to frame his findings than Cruickshank, Collins, and Minten (2014, 2015) and Frontiera (2010), Schroeder similarly found a critical early step included the new head coach clearly defining and articulating programmatic core values, which included relationship values, behavioral values, and strategic values. These 
values included the ways in which coaches and athletes should interact and communicate, the use of statistics to promote values (such as quality at-bats in the case of one softball coach), and core values as a vehicle to explain the path toward success.

The head coaches also utilized values-based actions as teaching tools to reinforce the values, including modeling; assignments; technology; and providing opportunities for autonomy, responsibility, and leadership. The coaches also noted that, once their athletes' leadership began to reflect the new values, the cultural foundation had been laid. The head coaches were also intentional with their use of punishment and reward to further their culture. While these were handed out in alignment with coaches' individual styles, coaches offered extrinsic (such as playing time or scholarships), as well as symbolic rewards (such as helmet stickers, unique gear, or preferential seating during travel) to reinforce athletes acting in accordance with the new value system. More frequently, however, the coaches described using punishment, which were explicitly linked to values. The severity of the punishment varied based on the offense, but the coaches also noted that certain punishments became cultural myths that were passed down to subsequent recruiting classes whose mere mention was enough to keep behaviors from deviating too far away from values. As an example, the author cited a softball coach who utilized physical punishment after her team lied about attending a party. The coach noted that, "It worked well. ... I'm telling you, only four players on [this year's] team did that, yet they're all, 'I don't want to do anything like that'" (Schroeder, 2010).

Along with enacting change on the current roster, the head coaches also described specific recruiting strategies they implemented to support their new cultures. The head coaches described a balancing act, in that they definitively were looking for talented potential studentathletes, but were also searching for qualities beyond talent, among them passion, coachability, character, and being team-oriented. The head coaches also specifically described body language 
as being an important indicator of some of these prized qualities. Culturally, the coaches also felt that once the culture took hold with the current players, it would perpetuate into the recruiting of future classes and, thus, make future recruiting easier. All coaches noted the importance of context, noting that certain factors beyond their control - institutional culture, available resources, and the administration among them - could facilitate or debilitate the integration and implementation of a new culture.

While these previous studies provide valuable insight into key aspects of culture change, there is limited research highlighting those within long-lasting and sustained high-performing cultures. Within sport, there may be no greater example of sustained success and an enduring culture than the New Zealand rugby side, the All Blacks. The All Blacks' sustained on-field dominance is best illustrated by their having won $75 \%$ of their test matches during their first 109 years. In the case of a legacy lasting that long, no single leader is responsible for success. These shifts in leadership have the potential to shift which value(s) dominate within the culture (Schein \& Schein, 2017; Sueldo \& Streimikiene, 2016). However, across generations of leaders, and their respective coaching styles, the All Blacks have maintained the core elements of their culture. Johnson and colleagues (2013) investigated the factors that have allowed the All Blacks to sustain their elite level of performance over the decades within their case study approach, specifically interviewing past and present captains and coaches integral to the side's success over the 60 year period of 1950-2010. Based on these interviews, the authors identified three main themes as integral to the All Blacks' success: Pride in Winning, Pride in the Legacy, and Embracing Change. Pride in Winning and Pride in the Legacy shared substantial overlap as both captains and coaches expressed a responsibility to win, describing a combination of motivational, emotional, perceptual, and cognitive processes. This responsibility was passed down to each subsequent generation, but not just for themselves - it was also for others 
including past members and their fellow New Zealanders. The All Black's valuing winning has likely achieved the status of becoming an underlying assumption given their rich history of success on the field. Moreover, Schein (Schein, 2010; Schein \& Schein, 2017) has described history as a cultural artifact.

Finally, the culture's ability to endure for more than a century is a reflection of its Embracing Change. While the All Blacks have deliberately maintained certain aspects of their culture, they have also demonstrated openness to making adjustments in an effort to ensure the continuation of their winning legacy and to continue to leverage culture as a competitive advantage across multiple leaders, generations of athletes, as well as more global societal changes. A prime example of this is the evolution of the roster's ethnic makeup. In the 1950's, the team was predominantly Pakeha, while half the starting side in the 2011 World Cup were Maori and Polynesian. While the core values have remained the same, these changes have influenced aspects of the All Blacks' culture - notably in the performance of the Haka (a prematch ritual performed by the team; Johnson et al., 2013).

Despite increased exploration of organizational culture in sport literature, the topic still lacks sufficient depth. Specifically, much of the research thus far has focused on two primary areas: sport administration (e.g., the larger organization or national governing bodies) or culture change (e.g., the processes and mechanisms through which poor-performing cultures attempt to change). These areas of research have highlighted the critical importance of developing a strong culture, but either fail to address the process(es) for development of a sustained elite performing culture or lack longitudinal considerations for sustaining the cultural strengthening.

Likewise, with the preponderance of culture research coming from business and organizational domains, the crossover focus on sport administrators (Cooper et al., 2014, 
Fletcher \& Arnold, 2011; Frontiera, 2010) makes intuitive sense given the overlap of sport and business in their job duties. However, culture is a daily process and not an isolated event. Especially at the college level, coaches - and not administrators - are the ones involved in the daily development and promotion of culture. The manner in which coaches opt to lead and develop their cultures can have personal and athletic influences beyond performance, including effects in areas such as relationships, well-being, and motivation. However, few studies have investigated the core values driving these leadership decisions and leadership behaviors.

Therefore, this study aimed to address this gap in the literature. The purpose of this study was to gain greater insight into collegiate head coaches' experiences and perceptions developing and implementing culture within their sustained high-performing programs. Within the broader question of culture development, the study looked at four sub-questions: 1) What are the core values that head coaches deem most important toward building sustained highperformance cultures?, 2) How are these core values taught?, 3) How do these values manifest in the actions/language/communication of those within these cultures?, and 4) How do coaches reinforce these values-based actions? How are coaches addressing actions that are not aligned with values? 


\section{METHODS}

\section{Paradigm}

This investigation was conducted from a postpositivist paradigm. Hatch (2002) asserts that this paradigm operates from the assumption that, because of the limitations of human inquiry, the inherent order of the universe can never be completely known. Therefore, reality can be approximated but not fully apprehended; postpositivist researchers work to capture close approximations. Those operating from this perspective do not believe in strict causes and effect, but alternatively recognize all cause and effect is a probability that may or may not occur (Creswell, 2013). Within this paradigm, researchers, themselves, are viewed as the research instrument and, therefore, it is paramount that the researcher maintain an objective perspective on the phenomenon being studied. Research techniques, such as analytic induction, are used to ensure that empirical data - and not the researcher's impressions - drive the findings. Data collection and analysis products from this paradigm lead to descriptions of patterned behavior that participants use to make sense of their social surroundings.

Generalizations are induced from systematic analysis of data that take the form of searches for patterns. When patterns are discovered, deductive processes are used to verify the strengths of those patterns in the overall data set (Hatch, 2002).

\section{Tradition}

The aim of this study was to understand head coaches' perspectives on core values and their roles as potential drivers of culture; therefore, the current investigation utilized a phenomenological tradition. Creswell (2013) described a phenomenological study as describing the common meaning for several individuals of their lived experiences of a concept or 
phenomenon. Creswell continues that the basic purpose of phenomenology is to reduce individual experiences with a phenomenon to a description of the universal essence.

One might argue that a postpositive approach and phenomenology make strange bedfellows. Intuitively, readers may question a perspective that casts doubt upon participants' ability to identify truth while simultaneously utilizing an approach that relies on participants' perspectives. While this is understandable, Racher and Robinson (2003) analyzed this specific paradigm-tradition fit and determined that the two were congruent. The authors noted Giorgio's (1992) assertion that not all interpretative approaches (such as a phenomenology) claim to be relativistic and, thus, differences between a postpositive and interpretive approach may be a matter of degrees or varying points on a continuum as opposed to dichotomous opposites. Moreover, phenomenology has been described as consistent with multiple paradigmatic streams (Annells, 1999; Clark, 1998; Guba \& Lincoln, 1994) - creating space for a range of approaches, from Husserlian to Heideggerian to a post-positivist approach taken by Merleau Ponty. Thus, Racher and Robinson (2003) concluded that reconciling paradigm assumptions was less of a concern than recognizing the value of different paradigm insights in developing new and evolving paradigm methodologies.

\section{Researcher's Role}

The author of the current investigation possesses more than a decade of collegiate coaching experience. Though working as a member of the support staff for the larger athletic program, the author was responsible for implementing and reinforcing core values and culture within his domain (strength and conditioning) for the various programs with which he worked. This experience was beneficial for the author's understanding of what and when to ask regarding specific follow-up questions during data collection, but was also something from 
which the author could not entirely separate himself. From a Husserlian perspective, the author attempted to bracket any potential preconceived notions, biases, and judgments; while the author's effectiveness is something readers will decide for themselves, the author's best efforts were utilized throughout data collection and analysis to be a transparent research instrument.

\section{Participants}

Purposeful sampling and intensity sampling techniques were utilized to select participants. Purposeful sampling refers to a sample specifically chosen because its participants can inform an understanding of the research problem and central phenomenon of the study (Creswell, 2013). Intensity sampling refers to selecting cases that are rich examples of the investigated topic (Patton, 2002). To ensure participants were able to provide appropriate depth to an inquiry of core values within sustained high-performing cultures, participants also had to meet the following inclusion criteria:

1. Participants must be current head coaches of NCAA Division I athletic programs. This is the highest level of intercollegiate athletics in the United States, as well as the level at which coaching salaries and its associated pressure to win are the greatest (Curtis, 2003, 2004).

2. Participants must be in their current head coaching position for at least five years prior to data collection (the academic years 2013-2014 through 2017-2018).

3. As a head coach, participants must have won at least one national championship, won at least two conference championships, and averaged a top-ten national ranking throughout the five seasons prior to data collection (academic years 2013-2014 through 2017-2018) according to the annual NACDA Learfield IMG College Directors' Cup standings (at least two out of three). The Directors' Cup awards points based on 
programs' advancing through postseason competition, but does not account for conference championships (NACDA, 2018).

4. Participants must have participated in postseason competition in each of the five seasons prior to data collection (academic years 2013-2014 through 2017-2018).

Inclusion criterion two was used to ensure that coaches have implemented and established their desired cultures within their programs for an extended time period. Moreover, this length of time ensured that participants led at least one full recruiting class through their current program and its culture. Criteria three and four were meant to serve as objective measures of successful on-field performance. Satisfying at least two of the three aspects of criterion three suggested the program had performed at an elite level over multiple seasons. Similarly, the argument of a program's sustaining elite performance would have been undermined if it failed to qualify for postseason participation (criterion four).

On the other hand, since this investigation focused on the larger macro culture of the program, certain sports' coaches (e.g., track and field, swimming) were excluded from the sample. In these sports, individual event coaches tend to have a greater influence on their respective athletes compared to the head coaches' direct influence. Thus, these programs tend to be more of a group of subcultures rather than a unified group and would have provided insight into different team dynamics than was intended for this investigation.

To control for potential differences in dynamics between genders or between team and individual sports, all participants in this study were female head coaches of female team sports. Twenty-eight such head coaches met eligibility criteria for inclusion in the current study. Of those, nine expressed interest in participation. Six of those nine coaches began data collection, with one participant withdrawing during data collection. Thus, five participants completed the 
study. These coaches lead programs in three different sports [field hockey $(n=3)$, basketball $(n=1)$, and softball $(n=1)]$ and which participate within three different athletic conferences. Through the 2018-2019 academic year, participants' years leading their current programs ranged from $11-38$ years (mean $\pm S D=24.6 \pm 12.38$ years). The head coaches led their current programs to numerous conference championships, ranging from 6-26 championships (16.6 \pm 8.99) across the sample, and national championships, ranging from 1-7 championships (2.8 \pm 2.49). Over the course of their respective head coaching careers, the five participants have totaled 157 years of head coaching experience, earning a total of 95 conference championships and 14 national championships.

\section{Data Sources and Collection Procedures}

Culture researchers (Cruickshank \& Collins, 2012; Cruickshank et al., 2013; Hofstetter \& Harpaz, 2015) have advocated that culture development and implementation is not solely a topdown process; culture's foundation in shared learning speaks to this collective process. However, the leader's role in shaping the culture was described in the previous chapter - with this role being especially pronounced in the case of collegiate athletics. Beyond differences in power dynamics, the nature of college sports dictates that student-athletes will only be active participants in the culture for a finite length of time (e.g., four years), while coaches (including those who participated in this study) often lead their cultures for far longer than that. For this reason, collegiate head coaches are extremely influential in shaping the programs' cultures. Disparate power dynamics notwithstanding, coaches can still empower their athletes with choice, voice, and autonomy as they lead and oversee their cultures. However, given the limited understanding in the literature, it was important to understand the dominant core values driving the macro cultures within these championship programs, why they are important, and 
how they are reinforced by collegiate head coaches. To that end, the current study aims to answer the following research question and sub-questions:

What are collegiate head coaches' experiences utilizing core values in leading their sustained elite performing cultures?

1. What are the core values that head coaches find most important toward building sustained high-performance cultures?

2. How are these core values taught within the culture?

3. How do the core values manifest in the actions/language/communication of those within the culture?

4. How do coaches reinforce these values-based actions? How do coaches address actions that are not aligned with values?

All prospective participants were contacted directly by the author via email or telephone. The author followed-up with interested coaches and set up a phone call to familiarize coaches with the basic format and purpose of the study. Head coaches in the study were voluntary participants and were free to withdraw at any time; verbal consent to participate was obtained during the familiarization discussion. At the conclusion of the familiarization discussion, the author scheduled the first interview with coaches expressing interest in participation; the informed consent document was also sent at this time for the coaches' review and signature. Due to logistical and geographical limitations, interviews were conducted via telephone.

Data in the current study were obtained via interview. Hatch (2002) described several important steps for qualitative interviewing, including that researchers utilize open-ended questions, encourage participants to explain their unique perspectives on the issue at hand, and 
listen intently for special language and other clues that reveal meaning structures informants use to understand their world. To accomplish this, semi-structured interviews were utilized in the current study. Semi-structured interviews enable researchers to maintain some consistency over the concepts that are covered in each interview, yet also maintain the flexibility to ask additional questions or follow-up on any salient topics that emerge during the interview process (Corbin \& Strauss, 2015; Hatch, 2002). Schein (Schein, 1990; Schein \& Schein, 2017) advocated for this type of open-ended questioning as integral toward developing an understanding of an organization's culture and values.

Interview scripts were developed by the primary researcher, though some questions were borrowed or adapted from previous literature (Frontiera, 2010; Schein \& Schein, 2017). The questions were designed to elicit a thorough description of head coaches' experiences implementing their core values within their programs' cultures. In alignment with recommendations from Seidman (2013), the current study utilized a three-interview format, each with its own overarching theme. According to Seidman, the goal of the first interview is to establish the context of the experience. In the present study, this meant identifying coaches' general operational definitions of core values and culture, understanding how those definitions specifically applied to the cultures of their programs, and understanding the background of why those core values were prized within their cultures. Questions were designed to elicit these explanations (e.g., What do "core values" mean to you?, What are the core values of your team's culture?, and Why are these specific core values important to you and your program?); the full list of questions from the first interview are available in Appendix A.

Seidman (2013) suggests that the aim of the second interview is to have participants reconstruct the details within which the experience occurred. In the present study, this focused on exploring the coaches' actual process of implementing the core values within their culture. 
Questions in this interview were designed to have coaches describe their initial and continued experience teaching culture, as well as provide insight into coaches' understandings of how the core values have taken hold within their programs (e.g., Describe the process by which you introduce your athletes to the program's core values., If I spent a day in your program, what things would be representative of your program's core values and team culture?, and How do you evaluate the degree to which the core values have taken hold?); the full list of questions from the second interview are listed in Appendix B.

Seidman (2013) suggests the third interview be used to encourage participants to reflect on the meaning of their experience. In the present study, this encouraged coaches to reflect on the larger meaning of the core values and culture related to student-athlete well-being and performance. Questions in this interview asked coaches to connect their cultures to constructs such as motivation, relationships, and performance (e.g., How would you characterize the relationships among your student-athletes?, How do you buffer against complacency?, and How often is winning discussed within your program?); the full list of questions from the third interview are listed in Appendix C.

Seidman (2013) suggested that each of the three interviews be conducted with a gap of between three days to a week between interviews. The author made every effort to follow this guideline in the present study, while also accommodating head coaches' busy schedules which did not always allow for it to be followed exactly. Three participants maintained a weekly schedule for interviews; however, one participant needed to reschedule interviews multiple times leading to an 18-week span between her first and final interview. In contrast, another participant requested that the schedule be condensed due to limited time; for this participant, the first two interviews were conducted on the same call with the third interview occurring two days later. Excluding these outliers, the remaining participants averaged 10.67 days between 
first and third interviews. Participants averaged a total of 90.66 minutes across their multiple interviews. All interviews were audio recorded, transcribed within 72 hours of their collection, and double-checked to ensure accuracy. Each interview was stored on a portable hard drive not connected to the internet, with a back-up version stored on a separate portable hard drive not connected to the internet. There were no known risks for participation in this study.

\section{Analysis Procedure}

The first cycle of coding in this investigation was open coded, specifically utilizing in vivo coding. In vivo coding refers to coding by words or phrases from the actual language found within the qualitative data, used by the participants themselves. In vivo coding is appropriate for studies that prioritize and honor the participant's voice (Saldaña, 2016) and aligned with a Husserlian descriptive approach (Christensen et al., 2017; Dowling, 2007). In vivo coding was considered appropriate toward facilitating the present study's aim of exploring head coaches' experiences implementing core values and their culture.

In vivo coding also served another important purpose in the current investigation. The author's educational background and coaching experiences have shaped certain beliefs about core values and culture development. Focusing the analysis on the participants' own words helped maintain a focus on the participants' perceptions and experiences. In this way, this analytic approach helped the author bracket his experiences and perceptions from those of the participants; bracketing preconceived opinions is an important part of Husserlian phenomenology (Dahlberg et al., 2008).

Second cycle coding utilized axial coding, which was used to reassemble the data that were split into in vivo codes. Axial coding was used to determine which codes in the research were dominant ones and which were the less important ones, and to reorganize the dataset: 
synonyms were crossed out, redundant codes were removed, and the best representative codes were selected (Boeije, 2010). Moreover, this method aimed to link categories and subcategories, looking at how they are related, specifying the properties and dimensions of a category.

Identifying codes and developing larger themes were also facilitated by analytic memos created by the author. Researchers, writing down ideas as data are collected and analyzed, attempt to formulate the process observed in the data and sketch out the flow of this process (Creswell, 2013). Memos were utilized to facilitate assembly of in vivo codes, as well to serve as a reference against which potential categories and themes were compared.

\section{Trustworthiness}

Lincoln and Guba (1985) describe trustworthiness as a means for naturalistic inquirers to apply rigor to their research and respond to accusations that their research is "sloppy" or "merely subjective." The authors described four criteria for establishing trustworthiness in qualitative research: credibility, transferability, dependability, and confirmability. Specific methods were utilized in the present study to address concerns about trustworthiness.

\section{Credibility}

Credibility provides an external check on the inquiry process. Lincoln and Guba (1985) suggest using techniques that make it more likely that credible findings and interpretations will be produced in the study. Among the techniques proposed by the authors, the current study utilized peer debriefing, member checks, and negative case analysis techniques in an effort to produce credible findings. 
Peer debriefing is a process of exposing oneself to a disinterested peer in a manner paralleling an analytic session and to purposefully explore aspects of the inquiry that might otherwise remain only implicit in the investigator's mind (Lincoln \& Guba, 1985). In the current study, peer evaluation served multiple purposes. First, the peer reviewers posed challenging questions, which helped the author confront potential biases, meanings, and interpretations of interview data. Additionally, the consultations challenged the quality of the findings, serving as opportunities to determine the legitimacy of findings.

Five peer debriefers were utilized in the current investigation. Two of the peer debriefers had backgrounds in education, two had backgrounds in business (one in human resources and organizational culture, the other with a background in professional sport), and the final peer debriefer was a current graduate student with qualitative analysis experience. Debriefers reviewed interview transcripts, noting salient points and key takeaways. During the process of developing themes, comments from debriefers were reviewed as findings started to take shape. During this process, debriefers, themselves, were also consulted to determine whether potential themes and subthemes were truly present in the data; this helped to make findings both more reflective of the data and more parsimonious.

A second effort to enhance the investigation's credibility was the utilization of member checks. With this technique, data, analytic categories, interpretations, and conclusions are tested with members of the stakeholder groups from which the data were collected; Lincoln and Guba (1985) describe this as the most crucial technique for establishing credibility. In the present study, the three-interview format facilitated the utilization of this technique, as data and interpretations were member-checked by the interviewees in situ or, upon review of the data, within subsequent interviews. 
Negative case analysis was also used to enhance the credibility of the present study. When using this technique, researchers are advised to continue to refine hypotheses until they account for all known cases without exception, attempting to eliminate outlier findings. However, Lincoln and Guba (1985) note the potential for extenuating circumstances in which outliers may be found - and even appropriate - and, thus, the hypothesis may not need to truly satisfy all cases. In the present study, possible outlier findings were considered against categories and themes emerging from the data to determine the appropriateness of potentially refining or expanding the categories.

\section{Transferability}

The second aspect of trustworthiness, transferability, can be demonstrated through the provision of a rich description of the context in which the investigation took place. Lincoln and Guba (1985) describe that whether or not the findings hold in another context is an empirical issue whose resolution depends on the degree of similarity between contexts. Thus, the aim of thick description is to provide enough contextual detail to allow others interested in making a transfer of the findings to reach their own conclusion about whether or not the transfer is possible. This author provided a rich description of the coaches' backgrounds and experiences implementing cultures across their varied sustained elite-performing programs, in part, to support the transferability - and ultimately trustworthiness - of the current study.

\section{Dependability}

Lincoln and Guba (1985) describe an audit process aimed at supporting an investigation's dependability. Like a fiscal audit, the authors proposed that auditors examine the process of the inquiry to determine its dependability. Moreover, the auditor is tasked with examining the study's data, findings, interpretations, and recommendations, and attest that 
they are supported by the data. Authors leave audit trials by keeping record of their data collection and analytic processes; this was done in the present study to protect against accusations that its data or findings lack dependability.

Additionally, transparency gives readers the opportunity to judge the investigation's dependability. The author's disclosure of potential biases which could affect the data, and his description of the processes through which he attempted to minimize and avoid their effects, were included to support the investigation's dependability. Likewise, the author's provision of a rich description was intended to further support this study's dependability by providing a clear understanding of the context in which the findings were obtained.

\section{Confirmability}

Just as an audit trail can be used to support an investigation's dependability, it also can determine its confirmability, neutrality and repeatability. Halpern (as cited in Lincoln \& Guba, 1985, p. 319-327) described six categories of the audit trail: raw data, data reduction and analysis products, data reconstruction and synthesis products, process notes, materials relating to intentions and dispositions, and instrument development information. Excepting instrument development information (which was not a part of the current investigation), all other categories were preserved and available for audit in the present study.

Beyond an audit trail, peer debrief sessions provided opportunities for outside perspectives which may not have been considered by the author - both in terms of data and methods. This helped the author remain focused on methods aligned with the intent of the study, and findings which honored the coaches' experiences. Moreover, member checks provided the author an opportunity to directly identify whether data and interpretations 
accurately reflected the coaches' experiences implementing their sustained high-performing cultures. 


\section{RESULTS}

Head coaches described core values as providing direction for their cultures and programs. While coaches described a spectrum of formality to their respective processes, it was clear that each coach had a set of key qualities they sought for their program. An important starting point for understanding the role of values was to first understand the values themselves; that is where this section will begin. Next, this section will discuss the ways in which the core values are taught. Finally, it will describe behaviors representative of the values (or not) and the ways in which coaches reinforce those behaviors to drive culture.

\section{Identifying Core Values}

The head coaches desired a variety of qualities that centered on two key areas: personal and athletic development, and relationships. The following sections, More Than Just the Game and Our Family, will explore specific elements of these categories as it relates to the head coaches' desired values within their cultures; a visual representation of the core value themes and subthemes can be found in Appendix D.

\section{More Than Just the Game}

Coaches described values that targeted character and growth within sport, but also in ways that transcended sport and could affect their student-athletes for the rest of their lives. Four subthemes emerged within More Than Just the Game, centered around excellence, growth, work ethic, and integrity.

\section{Pursuing Excellence}

All coaches talked about a commitment to, and pursuit of, excellence. As described by Participant 2, one of the field hockey coaches, this included "working to be your best every day." 
While the idea of pursuing athletic excellence may be intuitive, coaches added that the pursuit of excellence extended off the field as well. The pursuit of excellence included desirable competitive qualities in other domains of life as well as making good decisions.

For their student-athletes as competitors, coaches prized qualities such as intensity, commitment, aggressiveness, and competitiveness. Likewise, all coaches talked about their student-athletes' passion - loving the game and playing it with joy and enthusiasm. They noted that their student-athletes loved the game, enjoyed playing it, and that this love would be visible to anyone observing the program. Smiles, laughter, and fun would be visible, as well as athletes "attacking every drill with enthusiasm." Beyond passion, coaches also talked about wanting their athletes to be focused, which not only spoke to attentional control skills on the field, but also understanding on a grander scale where their efforts would best be directed. Participant 1, a field hockey coach, shared a story about a rival team focusing so intently on beating her team that the opponent symbolically hung her team's mascot in effigy on the team bus. In contrast to this external focus, she described her team's focus and view of competition differently:

Our competitiveness is more like golf, where you're trying to beat the course. ... We're just trying to be the best we can be. And I know those are words, and they're said a lot, "Just be the best you can be," but it really [emphasized] is important to get it right [emphasized] and not be obsessed and focused on the opponent. ... the competitiveness has to be: how can we be better than we were yesterday? That's where our competition comes in.

On the field, coaches wanted student-athletes who understand strategy and game play, making smart plays. In softball, that might be understanding to which base the ball should be 
thrown in certain defensive situations; in basketball, that might be understanding how an opponent is defending you and how to break that defensive scheme. Making good decisions on the field also included understanding (and committing to) program standards and expectations. As Participant 2 described:

We defend to win. And that's a habit that we have. When we don't have the ball, everyone is defending. When we do have the ball, everyone is attacking. So, I have these things. You protect the middle and everybody [emphasized] sprints back. It's not okay to jog back. And so, these are habits that we want to have on the field.

Aligned with being about more than just sport, the decisions the student-athletes made off the field also reflected their commitment to excellence and being the best competitors of which they are capable. Areas like nutrition, alcohol consumption, and sleep were mentioned by coaches as reflective of a commitment to excellence because of their impact on performance. Likewise, Participant 1 illustrated the pursuit of academic excellence in her program, saying:

One of our tenets is Make Decisions That Celebrate Your Greatness. ... If someone skips class, is that celebrating your greatness? No, obviously, it's not. ... Is it celebrating what we're trying to do here and celebrating what you're trying to do here? And usually, obviously, the answer is no, unless it's the correct decision."

\section{Continuous Improvement}

Additionally, coaches talked about wanting to help their student-athletes' development as both competitors on the field and as people off it. Coaches talked about "helping people do things they can't do themselves." In particular, Participant 3, a basketball coach, took a lot of pride in the way her team (as a whole) and student-athletes (as individuals) improve throughout the season. She noted: 
We're really excited about the improvement. I think that that's one of the things I'm probably most proud of is, the improvement of players, just how they come in as freshmen and people might think, "Well, why'd you recruit them?" and then they graduate as All-Americans.

Coaches also spoke of Continuous Improvement as something personally meaningful to them. Coaches talked about their efforts to continue to learn and grow, including through reading various sport, psychology, and leadership books. Moreover, Participant 4, a softball coach, described that learning and growth are integral to her program's ability to buffer complacency, saying, "You never think you know it all. You don't know it all. We ... try to get around a lot of successful people, a lot of different people, so they can continue to inspire us to get better in smaller areas of the program."

Likewise, coaches also talked about growth mindset as an element of Continuous Improvement. In describing why she values a growth mindset, Participant 5, a field hockey coach, highlighted the alternative in which, "people take themselves so seriously and they can't make mistakes and fear failure because you don't create an environment of exploratory learning for them." She and other coaches talked about using failure as fuel and being able to learn lessons from mistakes. As a leader, Participant 3 shared a personal example in which she erred by not dealing directly enough with issues earlier in her career. Learning from these earlier experiences helped her as she progressed in her career to more quickly recognize potential warning signs and deal with potential a problem "before it becomes, maybe, a bigger issue that it had [emphasized] to be."

\section{Work Ethic is Essential}


Coaches also emphatically emphasized the need for hard work and a strong work ethic. Some of the coaches mentioned it just a few times and treated it as an underlying assumption within their culture, while others mentioned it frequently. Regardless of frequency, it was clear that there was a strong need to "work hard every day" in these cultures. Coaches stressed the importance of hard work in practice, the weight room, and games as essential. In fact, Participant 4 described work ethic as her first step to jumpstart her program when she arrived there.

[I started] really trying to change the culture a bit with just work ethic on the field [emphasized]. ... So we needed to get working on [emphasized] the field. Just softball. And then I knew if we could get a softball-working mindset, then we started to build, from there, what a softball player [here] was: what we were on and off the field.

Embedded within the concept of work ethic is preparation - both that of the coaches, themselves, as well as their student-athletes. Video work as well as physically walking through things in practice were among the ways coaches helped their athletes practice small details and minimize surprises during the game. As a counterexample of work ethic and preparation, Participant 3 highlighted examples from earlier in her career in which players were more interested in partying than working in the gym. These players simultaneously described wanting to play professionally, but “didn't figure it out until it was too late. You can't wait until you're a senior, graduating, to get in the gym and work on your game."

\section{Acting with Integrity}

Another desired feature expressed by each head coach was that her people act honestly and with integrity. Coaches wanted their student-athletes to be good people. They described being dependable and punctual, as well as acting in accordance with athletic department and 
university guidelines related to the respective universities' Honor Codes. Participant 5 spoke passionately about the importance of integrity within her program, explaining, "I'm more into your integrity. Are you going to do what you say you do? And, if you put it on paper, then we're going to live by it or we're going to have consequences if it's not held to." Meanwhile, on the field, coaches talked about having no interest in the "hollow victory" that would come from cheating to win. Participant 2 explained that her program has "a reputation for playing clean, of not being a nasty group. ... We're respected."

\section{Our Family}

In addition to these More Than Just the Game values meant to help student-athletes develop academically, personally, and athletically, the head coaches also talked about relational values and the family atmospheres they wanted within their programs. All coaches stressed a family atmosphere in describing the connections between the people in their programs. These close, connected relationships were evident in the ways in which people worked together and related to each other within the programs' cultures, highlighted by subthemes of collaboration, authenticity, support, and respect.

\section{Collaborating with Each Other}

In order to perform at a high level, coaches talked about the need for collaboration. Within the team, coaches advocated for "cooperation", "being good teammates," working as "one big family getting after work," and "coming together toward a higher purpose." Participant 3 described that her student-athletes unleash their competitive side in practice, evident by "people really competing [emphasized], but I think in a collaborative way, helping each other get better." 
One of the primary elements of collaboration was communication, which coaches viewed as vital to facilitating elite performance on the field and keeping everyone on the same page off the field. On the field, coaches stressed that communication might be expressed in countless ways, both verbal (e.g., direct conversations) or non-verbal (e.g., high-fiving each other or even body language indicators that suggested engagement and interest). Participant 2 highlighted both the verbal and non-verbal communication methods related to her program's connection on the field, sharing:

It's always part of our game plan to have good communication, especially in the defensive area. You've got to have good communication. And communication is also eye contact and signaling. You can give, in our sport, hand signals, where you might feign one way and you're going the other. And the communication is you point. And your teammate sees it and the defender doesn't.

Importantly, coaches stressed the importance of empowerment within their cultures. In contrast to authoritarian leadership, these coaches all talked about including their studentathletes (and specifically team leaders) in directing the group. Coaches, understandably, reserved the right to make final judgments as they steer culture, but they stated intent in wanting to work alongside their student-athletes in a collaborative - rather than top-down manner. Participant 1 addressed this topic as she contrasted her culture against a hierarchical pyramid with coaches at the top and student-athletes at the bottom; this structure, she said, made their culture nimbler and more responsive:

We look at it as a circle, so that everyone [emphasized] is of equal importance. ... And, that allows a first-year player to step forward and make a contribution, or make a suggestion. Whereas if you're kind of in a hierarchical setup, that, you know, sometimes 
the really important information that's at the bottom of the pyramid never gets to the top of the pyramid. The head coach or the assistant coaches can affect change, but if we don't get the information, it's really hard to have any change. ... I think that shapes our team culture.

In contrast to these collaborative efforts to work together, the coaches all stressed the harmful effects of selfish behaviors within the group. Coaches noted that group needs took priority over individual wants and described selfish behavior as "intolerable" to team success. As Participant 5 stated it, "Sometimes the individual may not be able to benefit at the expense of the group, but the group can never be compromised by an individual."

\section{Authentically You}

Coaches emphasized that people needed to be themselves for the program to be at its best. A culture placing a premium on authenticity allows people to "be who they are." Coaches stressed that authenticity was important both for themselves as leaders, but also for their student-athletes to thrive as competitors and people. Participant 4 stated that people compete differently, but a culture in which people felt comfortable being themselves allowed them to express "their competitor" in a healthy and effective way:

I feel like the more comfortable you get as a person, and the more comfortable you can [emphasized] be as a person, around the entire program, you're allowed to let your competitive nature be real [emphasized] because you don't feel as if you're being judged or looked at differently. ... Their ability to be who they are [would be visible], so they can compete who they are. 
Participant 5 took it a step further, stating that her "number one core value is authenticity. You have to be [emphasized] yourself, and you can't pretend to be anyone else. And that's what I always work to instill in the women that I coach. [pause] Find your voice, find your way."

In order to be authentic, coaches talked about the need for vulnerability and trust. They felt that vulnerability was required in order to expose one's true self, to the group. It was important for members of the group to communicate openly and vulnerably - and feel secure that their vulnerability would not be used against them in any way. In some circles within sport, vulnerability is viewed as weakness; not so according to Participant 1: "I think that vulnerability is a way to strengthen [emphasized] the team; it doesn't weaken the team. I think people get very confused about that." This idea was shared by other coaches in the sample, believing that with open, authentic relationships, comfort and vulnerability could serve to galvanize the group. Participant 4 said, "The more I can get them comfortable in their own skin, comfortable around me, the more they're able to be vulnerable, the better we're going to grow as a team, the stronger unit we're going to have."

Coaches advocated for trusting relationships that extended both on the field and off. Trust, they felt, was an integral component toward people displaying vulnerability, as well as being able to authentically be themselves - as both people and competitors. Thus, while coaches mentioned the ability to trust in a teammate to demonstrate qualities prized within these cultures, they also emphasized that trust more generally allowed people to simply be themselves and strive for excellence. As leaders of elite programs, the coaches and players in these sustained high-performing cultures are often playing on the biggest stages in their respective sports. Some athletes will play conservatively on these grander stages, aiming to avoid mistakes rather than relying on their training and preparation to guide their performance. 
Participant 2 highlighted how trust can facilitate these athletes in their quest to "dare to be brilliant:"

Mistakes are made all [emphasized] the time. And so there has to be some level of comfort in making a mistake. ... If you have a good culture [emphasized], there's the trust to "dare to be brilliant," to try things that you might not necessarily try or could be construed as being risky. You can't be afraid when you're playing, especially when you're in a championship game. That championship [emphasized] game, sometimes that heightens [emphasized] the level of stress and pressure to perform. ... And so, if you do have a healthy culture, I think you have more freedom [emphasized] to be your best.

\section{Supporting Each Other}

Coaches described the relationships within their cultures as being encouraging, welcoming, and happy for each other's successes in both word and deed. Participant 3 noted that her student-athletes helped, communicated, and encouraged each other, adding as evidence that they are "cheering for each other in the games or encouraging each other in practice." These relationships can be especially important on the personal side. Participant 5 described during her interviews that an international player had recently incurred a serious injury. By all indication, this student-athlete was headed for a major surgery and recovery period, as well as needing to adjust to having the game taken away from her and a very different role within the team. However, the coach mentioned that one of the reasons the studentathlete was considering staying - rather than returning home - for the surgery was that "she has a support network in her teammates and her coaches here, a family far away from home." Or, as stated by Participant 3: 
We've had sets of sisters on our team, or twins on our team, and I think in watching how they relate to each other, that has set the tone for how we want all of our players to relate with each other. ... a very strong sisterhood of caring, and respecting, and encouraging, and being a support system for each other.

\section{Respecting Each Other}

Coaches talked about the importance of developing respectful relationships within their sustained high-performing cultures; these relationship dynamics applied to every member of the culture - not just between the athletes or as a one-way street from athletes to coaches. While coaches aimed for familial relationships, they noted that - at minimum - relationships needed to be mutually respectful throughout the program in order for student-athletes to optimize their performance and their experience together. Several noteworthy counterexamples have been detailed in the media, including a football player dying of heatstroke at the University of Maryland during summer workouts in 2018; according to reports following the incident, the player's death was the result of a "toxic" culture featuring fear, intimidation, and verbal abuse (espn.com, 2018). Participant 1 made clear that those things had no place in her culture:

People can [lead] through humiliation, intimidation, bullying, fear tactics. And they do! But [sigh], it's so dehumanizing. ... [The player at Maryland is] an extreme example of what can happen if your team culture is really misguided because people are just so focused on the results. And, they figure, that's the shortest way or the most convenient way, or maybe for them, the most effective way to get there. But we've found a way to really coach with compassion, empathy, empowerment [emphasized], and win championships.

\section{Teaching Core Values}


Having identified the core values of these sustained elite performing cultures, the next question was to understand the process(es) through which the coaches teach the core values to their student-athletes. Unsurprisingly, all coaches stressed the importance of communicating their values with their teams, though each had their own preferred methods of doing so. Several participants talked about it being done early in the fall, with Participant 3 emphasizing that it is the "very first [emphasized] things we do." Meanwhile, Participant 4, the only coach in this sample leading a spring sport, preferred to give her student-athletes some time to acclimate to the new year before "planting seeds for the season." Despite differences in the organization of the rollout, coaches utilized several methods of teaching the values. Consistently, coaches utilized written documents and collaborated to define core values. Less consistently, two other noteworthy methods for teaching core values also emerged from the conversations, which included not waiting until people get on campus and utilizing other instructors.

\section{Putting Them on Paper}

Despite semantics differences in how some coaches referred to their program's core values (e.g., cultural "habits" or "expectations"), all coaches described utilizing a written document as a teaching tool. Even Participant 2, who said that she does not have the core values explicitly written out, described utilizing a written document with incoming freshmen that also was given to their parents. Many of the previously-described values associated with these sustained elite-performing programs were covered within these manuals, including: player expectations on and off the field, playing principles, and preferred communication methods including a clear explanation of certain things coaches expected to address with players and not parents (e.g., scholarships or playing time). Participant 3 even went a step beyond merely presenting and discussing this information with her student-athletes; she described having her student-athletes sign the document to verify that they understood what was expected of them 
within the culture. Regardless of the specific artifact used, all coaches explained that their written document served as a springboard for further discussion, presentation, and explanation.

\section{Defining Values Together}

Developing a shared definition was critical because the same words or phrases could carry vastly different meanings for those in the group. Participant 4 explained:

When I say the word "family," you're going to go with what your family looks like and how your family lives, where in my mind I go to what my family looks like and mine lives. And they may be two completely different ones. I have divorced parents. We have a small family. We didn't eat dinner at the dinner table every night, where maybe you ate dinner at the dinner table with a lot of brothers and sisters.

Coaches wanted their players involved in defining the core values, both as a way to empower the athletes and to enhance buy-in from them. In Participant 2's words, "Some of those [values] are dictated by the team. And especially now, with this generation of kid, I think the buy-in is super, super important. So, when it comes from them [emphasized], it's just far easier for them to abide by." While each coach had their own specifics for going through this process, it commonly included splitting the team into small groups (each with different classes represented). The small groups worked through what it looked like to live the value, with veteran players often providing cultural examples since "freshmen are probably not going to come in demonstrating core values from day one." As smaller groups started to define the values, they would then present it to the rest of the team; this definition process also laid the groundwork for future discussion and elaboration of the value and what living it would look like.

In addition to culture being a fluid construct, so, too, are rosters at the college level. Whether due to injuries, transfers, graduation, new incoming recruits, as well as countless other 
reasons, the make-up and dynamics of each year's team differs. Given this fluidity, Participant 4 recognized that each group needs to understand for themselves what the programs' expectations are and how to abide by them:

It's a [pause] communication of the people that are part of the team, because the team's going to change every year. So, it's going to be my program. I'm the head coach of [this] softball program [emphasized]. It's their [emphasized] team. So, it's going to be a different team each and every year and, within the year, the team's going to change a little bit, too, because players are going to leave, or people are going to get hurt. There's going to be some different things happen. So, I think from the top, there's going to be a program and a way things are run [emphasized] and a standard [emphasized]. It's their team [emphasized] to figure out how to manage through the season.

In other programs, this definitional collaboration was reflected by coaches encouraging their student-athletes to develop a mantra for that year's team to represent what living the core values meant to them. As Participant 5 explained:

Last year's group, they had a three-letter logo that meant something to them. ... This year's group, they came up with it and worked on it through the spring. It's - they still have their culture, values, but their theme [emphasized] ... Each group kind of comes up with their own identity within the confines of the culture of [our program].

Further collaboration was evident in coaches' utilization of support staff to teach core values to their student-athletes. Two coaches mentioned utilizing their sport psychologist to teach values to the team. Meanwhile, Participant 3, a basketball coach, explained that her strength and conditioning coach is an important piece of teaching her program's values, especially with NCAA rules limiting contact over the summer. "She's letting them know, 'Here 
are the expectations' ... so they're getting a little dose of what it's going to be like" when the academic year begins in the fall.

\section{Early Introduction}

Meanwhile, coaches expressed mixed experiences utilizing core values within recruiting. Three coaches stated that core values and culture had little role in their recruiting pitch nowadays - especially in relation to the importance they once held in the process. Coaches cited as reasons for this shift changes to the recruiting process (e.g., the early age at which recruits commit to schools), generational factors, and even simply a limited pool of applicants that can meet both their universities' athletic and academic standards. Conversely, Participant 1 said that she and her staff introduce the core values in recruiting and spend a lot of time "recruiting the parents" making sure they are "on board with the core values."

Participant 4 went a step further indicating that recruiting was an integral part of teaching core values. The first chance she is allowed by NCAA rules, she sends committed recruits a letter related to their core values - such as a definition or a picture. She follows up with additional contacts later, asking the recruits to send her a definition, image, or example of what a value looks like in their lives. By having these back-and-forth exchanges with committed recruits, she gains an understanding of the athletes' connection to the program's values which informs what guidance the recruits might need once they actually arrive on campus. In her words:

I send them the definition of Family, and then I'll send a picture or I'll do something - I'll send it to them, and then, maybe, a month or two later, I'll email them and say, "Tell me what Smart would look like in your [emphasized] daily routine." ... She sent me her idea of what Smart meant for her [emphasized], which was making sure she got to bed at 
night because she gets up really early, and then she has really long days. She takes care of her little sisters. She does things that - so now, all-of-a-sudden, she's talking about her core values, defining it through our core values. So when she comes in, her and I don't have to talk about Smart. And then, when she comes in as a freshman we'll talk about [our] Family, and how we do things here as Smart. So, I introduce it to them before they even get here in college, and then we live it in [emphasized] college.

\section{Teammates Teaching}

Another noteworthy method of teaching the core values was utilized by a single coach. Most coaches spoke of the informal influence their veteran athletes might have on new members of the culture through modeling the correct behaviors. Participant 5, however, described a process in which she met with team leaders in the summer to go over key cultural objectives, reviewed them with the leaders, and prepared the leaders to teach them to the incoming freshmen class. Following the instruction, the coach would check in with the incoming freshmen to gauge their understanding of the program's values and culture. She added that in the upcoming summer she planned to give the freshmen a written test to assess their understanding of the culture and values prior to her program's normal processes once preseason started in the fall.

\section{Living Core Values}

The previous section identified and introduced the values. The next section examines research sub-questions about what it looked like to live these values (or not) and, finally, what coaches did to either support or redirect these behaviors. However, the data revealed considerable overlap in these areas. For example, coaches described situations in which their team leaders addressed teammates not acting in accordance with the program's values. 
Depending on perspective, one could reasonably argue that a group of athletes demonstrated behaviors misaligned with values; meanwhile, it could just as easily be argued that the team leaders not only acted in alignment with the values, but reinforced the values' importance for their teammates. Additionally, situations in which the coaches behaved in accordance with (and modeled) the program's values also served as situations in which the coaches were reinforcing the values to their student-athletes as important. Therefore, it seemed most appropriate to answer these research sub-questions together and consider what core values looked like when taken off the page and brought to life.

All coaches strongly emphasized that for as important as it was to teach the values, that bringing them to life required consistent, intentional, and daily effort. Coaches described practice as a prime place for bringing the values to life. Practice plans were designed to challenge athletes' actions and performance. Meanwhile, coaches also utilized pre-practice conversations to similarly focus athletes for that day's practice; Participant 3 describes:

Before every practice, we circle up and we talk about, kind of, the things that we're going to work on that day, the things that we want everyone [emphasized] to buy into: communicating, being vocal in practice, challenge [emphasized] and being competitive in practice, improving, being really - buying into improving. ... And, just, really spending yourself out there. Give everything you have for that two- or three-hour practice.

Meanwhile, cultural artifacts like signage and messaging throughout team facilities also served as constant reminders of core values. Rather than being left as teachers themselves, though, the core values opened up conversations to more deeply explore the values and what it would look like to put them into action. Participant 4 said, "It's one thing to write words on a wall and have 
a mission statement, but if you don't live [emphasized] it, and if you don't go up and down through the gray areas, you're not really learning about yourselves as a team."

Across all participants, several examples of each of these core values were discussed. With the core values already having been described, the following sections are meant to serve as especially vivid and illustrative examples of the core values in action - either being brought to life through values-based actions (VBA) or through actions not aligned with core values.

\section{Bringing the Pursuit of Excellence to Life}

Off the field, coaches wanted the pursuit of excellence to include student-athletes' work in the classroom. As people surpassed the acceptable standard or fell below it, coaches utilized both the "carrot and the stick." For those performing well, coaches publicly praised team members, as well as (in one case) provided shirts for those demonstrating excellence. Studentathletes not meeting the standard were assigned additional mandatory hours of study hall or additional supervised work to help them meet expectations.

As is common across college campuses, these coaches spoke of alcohol as a challenge to pursuing excellence. While coaches did not suggest it was an overwhelming problem, its accessibility to a group of people experiencing newfound freedom (freshmen) make it a constant presence. Participant 1 stressed that, despite occurring infrequently, they want their student-athletes to make good decisions and that there are consequences for violating the standards:

Those people are either suspended for a game, or suspended for a week. So once an activity that they love is taken away from them because of some bad judgment, they pretty quickly learn that that kind of behavior is not going to be tolerated. ... And, again, 
it's not a major [emphasized] thing, but it's enough of a thing that we we're just not going to tolerate it.

On the field, competition was a crucial element of pursuing excellence. Meanings of competition seemed to be individualized to the specific coaches, but all spoke of its importance. Some coaches looked at competition through the lens of wins and losses, while others compared it with elements like commitment and work ethic. Despite their varied perspectives, however, coaches described competition as a key for buffering complacency within their programs.

Team sayings and video were also used to reinforce values for the student-athletes. Coaches described oft-repeated cultural sayings as ways to reinforce their values. Sayings such as, "Make decisions that celebrate your greatness," "With each other, for each other," and "All in" were used to reinforce values of making good decisions, supporting and working with each other, and commitment. Additionally, coaches utilized video review of practices and games to both illustrate instances where athletic values were being lived as well as where they were not. Video was employed in various ways by these coaches: some video sessions were with the whole team, others in small groups, while others were done individually; some sessions were led by coaches, others by the players. Participant 2 described utilizing instances in which both their playing values were being lived as well as when they were not. She added that, even though one person might have made a mistake, it was something everyone could learn from:

We'll show [emphasized] negatives and we'll show positives, and then that's the way we always do it. So, if a core value is If you turn the ball, over we stop - we say, stop on a dime. We've been using that all the time [emphasized], that you've got to stop immediately and get back. And a pet peeve is when they don't [emphasized] stop on a 
dime, and they round off [emphasized]. You know, you take four more steps and then you round off. You got to stop [emphasized] and get straight back! So that's a big core value of ours. So you show [emphasized] that on video, and you show when somebody does it well [emphasized], and you show when somebody doesn't do it well. And that gets shown repeatedly [emphasized] because it happens, but it happens less and less [emphasized] because nobody wants to see themselves not stop on a dime.

\section{Bringing Continuous Improvement to Life}

The value of growth represented a clear indication of coaches' personal values overlapping with their programs' values. Some coaches connected growth with their own personal identity, describing themselves as learners and readers. Participant 1 described learning from books written by a mentor, but also understood the need to filter ideas and consider which ideas would be a fit for her program and her personality. In contrast to overworking her student-athletes, her growth taught her that there were better ways to productively channel her energy:

As you grow [emphasized] in the profession, you learn that less is oftentimes more. You just have to find a different way to channel your intensity and being driven. Maybe you [emphasized] watch more game film, as opposed to having your team practice longer.... And then when you had people like Pat Summit start writing books, and also learning from her [emphasized] mistakes, then it helped me reflect on some of the things that I was doing, and could do better [emphasized].

Participant 5 shared that she utilized a book club to help her team grow. At different times, she might have the whole team read the same book; other times, she might have different classes read different books - or even just connect individually with a student-athlete 
to share a potential book that may offer insight into something specific. She also detailed a conversation with her team about the United States Women's National Soccer team's recent public fight for equal pay as a springboard to a deeper conversation about equal pay between men and women. She added, "I really like to challenge people to think [emphasized] and grow, to be different than you are today. That's an important thing for me." Conversely, Participant 4 provided a counterexample for the effectiveness of a book club as a tool for growth in sharing a story about a colleague of hers (NOTE: the colleague was a male coach who would have satisfied inclusion/exclusion criteria for this study). His team, she described, reads the same book every year. Thus, rather than being a growth opportunity for the team it elicited frustration and annoyance from veteran players as the exercise grows stale.

Coaches utilized other mechanisms for growth as well. Coaches modeled the importance of improvement through their use of feedback; in addition to providing it to their student-athletes, many of the coaches emphasized it as a two-way street with their athletes reinforcing its importance as information (rather than personal attacks as it might otherwise be misconstrued). Coaches also described using video review with their teams to help their student-athletes grow as performers. Some coaches preferred to lead the video themselves, while others empowered their athletes to lead the sessions for their teammates. In one case, Participant 3 added that she includes written feedback within her video work; this gives the athlete feedback on things they are doing well and others that need more attention. Going a step further, Participant 4 described joining her student-athletes when they worked camps and clinics. Rather than having these camps and clinics be mindless work, she uses it as an opportunity to assess their understanding - and grow their understanding:

So our players work summer camp. But I'm not just going to have them go do pitching or infield or outfield. I'm going to go with them. I'm going to have them teach the pitching, 
the infield, the drill. And then I'm going to ask them, "Well, why [emphasized] are we doing this? What are we doing? Why are you having the kids do it? Why are we stretching like this? Tell me why." Because it's telling [emphasized] them, "Let me know you know [emphasized] exactly what you're talking about." And then you gain some confidence in yourself when you start to teach it yourself. Because a coach, a lot of times, we like to, say it, say it, say it, say it. And yes, the players will do it because you've been saying it, but do they really believe [emphasized] in it? Do they know how to troubleshoot it? Do they have confidence in it? Or are they just doing it because you said it? So, I think we really gain in the growth part of it, like not only in softball skills, but for the off-the-field values part.

\section{Bringing Work Ethic to Life}

Limited specific examples of living a strong (or lackluster) work ethic were described by the coaches due the investigator's (and readers') implied understanding of what it looks like. However, that is not to diminish its importance to the coaches. As previously described, Participant 4 made work ethic on the field her first priority when she took over as head coach. Meanwhile, coaches emphasized the trust and respect earned from a demonstrated strong work ethic; Participant 1 added that their hardest worker is rewarded with a special scrimmage vest, which also serves as a "a visible reminder to the rest of the team that if you work hard [emphasized], you're recognized."

Similarly, other coaches reflected back to early in their tenures and cited examples of student-athletes who did not want to live up to the new standard and work ethic that was being established within the programs. Participant 2 described losing some talented players because they were not willing to give the necessary effort: 
We lost some of the kids that didn't want to work hard. So, I came in and started training the team the way it needed to train if it wanted to be really good. And there was probably a core group that just quit right away, who were on the team, they could have been starters. But they didn't want to work [emphasized] that hard.

Certainly, the coaches all still look for hard work from their student-athletes, holding them accountable to the desired standard of performance. Participant 5 mentioned that if someone were to observe one of her team's practices that hard work would be evident, saying, "You'd see hard work. We touch lines, and we all finish our markers. And if we don't, we all do it again [laughs]. Or, depending where we are, some people keep going until they meet their standards."

\section{Bringing Integrity to Life}

The core value of Acting with Integrity was embodied by honesty, dependability, and following-through on one's word. While this is certainly the intent, coaches described situations in which participants did not always do so. In one case related by Participant 2 , a hurricane was making its way to campus and one particular student-athlete said that she preferred, understandably, to go home and ride out the storm with her family; however, that is not what happened:

We had a couple of home games and because this hurricane was turning like it was coming up, they cancelled classes. And so, some of the girls, I guess - this one girl said she was leaving to go to a safer place. So she had arranged to get out of [town] because this is where the hurricane was going to hit. And, so, in effect, the hurricane missed us. It changed tracks. And we were able to have practice. And we had [emphasized] practice. But apparently, this kid didn't [emphasized] leave town, but she did not come 
to the practice that we had. And so, she had lied about - she came to me and said, "I left and then I came back," but in effect, she never left.

Participant 2 had not been made aware that the student-athlete remained in town, though the rest of her teammates knew. And, with what was described as a very strong leadership group, the rest of the team had a very tough conversation with this student-athlete in which they clearly explained that behavior like this was not representative of the team; they said, "Look. You can't do this. You can't - you're representing us poorly and that's not who we are. So if you want to be part of the team, you need to change." Participant 2 found out about this after the fact, but said that she was proud of the team for the way the situation was handled - not only for maintaining standards and holding each other accountable to them, but for the impact of that message coming from teammates compared to coaches:

Well, truly, I'd rather the team handle it because then you're empowering the team to reinforce the team values, and who they want to be. ... And so, if the team can handle that, it's just far more meaningful to the person. Whatever's happening, when your teammates [emphasized] have these conversations, that - rather than the coach. The coach is going to always be viewed as this superior and so, to me, if the team can handle it, it's the better way to go.

In a similar spirit of collaboration, Participant 5 described an alternate situation in which she let her leadership group establish team rules. Leaders had differing views on what the standard should be for alcohol that year. She decided to let them work through the issue, but also challenged them to follow-through with whatever rule they set:

My whole thing all the time is, "Well, whatever you set, let's agree to live by it." [laughs] So, one year, we had two players that were dead-set on absolutely no drinking. And 
then the other three, in like what would be a leadership group, were like, "Well, we're fine, moderation." And I sit in on these discussions and facilitate questions based off of what you hear them talking about. And, my challenge is, "Okay. If this is the best player on the team, are you going to turn them in for drinking? Or are you going to think, 'We think we need that player to win the game.'" And, so you got to challenge them with those types of thoughts. And basically, the two that were absolutely [pause] no drinking were able to come a little more to the left, and those that were, like, not really cared about it were able to structure and create rules.

\section{Bringing Collaboration to Life}

Coaches provided a number of strong examples of how they bring collaboration to life. Participant 4 shared a story about her team recognizing the team around the team - everyone that is a part of the program that helps it function at a high level. In this case, the team wanted to express their gratitude for the janitor who cleans their facility. Unbeknownst to Participant 4, the players pooled some of their per diem money to buy a Christmas card and gift for the janitor and her daughter. In fact, Participant 4 said that she only discovered that her team had done this when she arrived in the locker room and saw the note the team had written for the janitor and her daughter. "I was blown away by how much the team was caring [emphasized] about somebody else and something else. And, but you could see [emphasized] that their culture was caring and family, and all about each other and connecting."

Coaches also emphasized the team around the team (e.g., their assistant coaches and support staff) as critical elements toward being able to bring the culture to life. Strength and conditioning coaches, for example, were involved in teaching the values and standards, while sport psychologists were utilized by several programs to facilitate defining the values as well as 
creating a forum where frank, challenging conversations could take place. As Participant 2 described, her team's sessions with a sport psychologist included some mental skills training, but also some communication training.

The sessions where we actually talk about [difficult] things helps give our studentathletes confidence [emphasized] to communicate, and to communicate under pressure and to try to do it in a manner that is well-received and calm and composed. So it's almost some training [emphasized] to communication. And it doesn't happen with [the sport psychologist] on the field [emphasized] but the habits are reinforced in those sessions, and then we try [emphasized] and apply them on the field.

She added that the communication off the field helped their communication on the field.

Moreover, coaches talked about being intentional about working to keep everyone on the same page, including regular meetings with both their assistant coaches and their support staff. Maintaining appropriate confidentiality (where applicable), coaches also talked about utilizing the strength of the collective group to triangulate things within the program that might need attention. They also talked various feedback processes in which they could both give and receive feedback from assistant coaches, support staff, and the student-athletes.

Empowerment was another element of collaboration strongly emphasized by the coaches. Coaches highlighted several examples in which they gave their athletes voice and choice, as opposed to dictating directions to them. Participant 4 described giving her studentathletes responsibilities, such as organizing meals for team events. In her opinion, either the athletes would take advantage of the leadership opportunity or there would be a great opportunity to reconnect to program values and standards if some people were unhappy with the selection. As she said, “If players aren't happy with certain meals, all we have to do is talk 
about it. 'How did you talk about it?' And then we go back to being a Family. Like, 'You have to speak your mind.' 'You have to be adjustable.'" On the field, one example of empowerment included giving student-athletes room to confer with each other during halftime of games to be problem-solvers for challenges presented by the opponent. Another example described giving players room to lead film sessions or to stop drills in practice and make corrections. As Participant 1 describes, she felt that empowering her athletes was an essential part of their culture, despite an obvious limitation that might cause other coaches to choose a different way:

The only limiting factor is that it just takes more time. Now, the most expedient way to do this is to have the team of 26 players sit in the team room, and us go through the video and point out corrections. Yeah, that's the quickest way. So, to do this playercentered approach, it just takes a lot [emphasized] more time. So, we're limited with 20 hours a week during season. So, you're going to have to give up part of practice [emphasized] to do it. But we do feel that it's that valuable, that I'm willing to do that.

Finally, coaches mentioned leadership as another important area of collaboration within their programs. Leadership was described as being critical for team success and, by some coaches, as the thing that separated their best teams from others. Importantly, coaches stressed that, despite a positive connotation, leadership can also reflect bringing people away from VBAs. Participant 3 described:

We have had some teams that have struggled with [leadership] and I think that part of it is - when you have a void [emphasized] of leadership and then you have a ringleader. A ringleader is charismatic, but they're not on the same wavelength as, maybe, the coaches, or, I would describe the culture. So, you might have someone that comes along and their [emphasized] version of playing collegiate basketball is partying Thursday, 
Friday, Saturday night and, just, getting to practice one minute before they're supposed to get there, not staying after extra at all, just being caught up in their own statistics.

To combat these negative influencers, coaches stressed maintaining strong lines of direct communication. They also utilized leadership groups to ensure that important information from coaches made it to the rest of the team, and that the team's important information made it to the coaches. Further, coaches described developing mentorships within the program, and being intentional about which players got paired together to grow leadership and minimize potential negative influence.

\section{Bringing Authenticity to Life}

Authenticity was a critical element of being able to perform, compete, grow, and even lead within these programs. As the leaders of the culture, coaches set the core values. They stressed that they needed to be authentic and lead in an honest way. Participant 1 stated that coaches better be living the core values, themselves, if they wanted anyone else in the culture to do the same:

It starts with the coaching staff. I mean, obviously, if we say one of the core values is Valuing Everybody, then the coaching staff better embrace that and interact with the players in a way that's respectful, and which shows our appreciation for their efforts, um, treat everyone the same. So, you know, it has to start with the coaching staff. We need to demonstrate that every day. ... Remember, obviously, core values are just words. So, unless you're demonstrating it every day with your coaching staff, and the people that are leading your team, then it's a little bit like leadership. You know, if you turn around and no one's following you, basically you just are taking a nice walk. 
Participant 2 shared a similar story about authenticity and value congruence when it came to behaviors within her culture. She mentioned that an opponent used to play kickball before the game. Preferring something more closely related to their sport, her team developed a game for pregame warm-up that is both "fun and within the game" of field hockey.

Part of authenticity, coaches stressed, is finding a good cultural match. When athletes were not able or willing to meet cultural standards, it occasionally progressed to coaches needing to have difficult conversations with athletes about the need to separate - essentially for them to find a better cultural fit. Expectedly, this also came up in recruiting. Coaches tried to identify people with similar values who would embrace the programs' values and flourish within them. From a recruit's perspective, Participant 4 talked about the need for congruence to allow athletes to compete at their best:

I think you've [emphasized] got to find the right culture that fits you [emphasized], so you can allow yourself to be who you are. So if you're the most competitive person and cutthroat, then you want to be a part of a program that could care less about the kumbaya, and you're just all about winning and cutthroat. And that's where you're going to grow as a person, and that's what you're going to do. If you want to go into a teaching program, and a teaching culture, a "that's going to grow you as a person" culture, then you try to find that place because that's where you're going to flourish. And, I think when you have comfort in your own skin, then you're allowed [emphasized] to do those things, and then you're going to come out even bigger [emphasized], as a bigger performer of your skill sets. ... So you're not worrying about judgment because you're in an environment that you feel safe with $17,18,19$ other people. 
In accordance with coaches' living and prizing these values, they talked about instances in recruiting in which red flags led to their ending the recruitment of certain players. Meanwhile, coaches talked about the importance of doing their homework in recruiting as they looked to identify potential recruits who truly live the values of their programs and who will embrace and enjoy a challenging four years as a student-athlete there.

\section{Bringing Support to Life}

Coaches mentioned that even amid competition in practice or for playing time, they continued stressing the importance of supporting each other and that players followed the lead. Participant 3 explained that even in situations where her athletes went against each other oneon-one, they still understood the bigger picture; she explained, "One person wins a drill or someone, they're - someone might make a nice move on somebody, they'll say, 'Good shot,' even though they scored on them [emphasized]. They're not sour." In addition to the athletes supporting each other, she continued to explain that support also came from the coaching staff. She explained that she and her staff aim to be complimentary, but that when corrections need to be made, they want to be direct in giving their student-athletes specific information on what needs to be done differently. She said that such feedback might sound like:

"Hey, you're working hard. You need to cut off the baseline," or, "Great defense there. [inaudible] effort. You've got to box out. Let's see you do that." Just, kind of, complimenting them, but being very direct in what you need them to do. But not [emphasized] in a derogatory way, not in a tearing them down way, but more like, "You can do this. Let's work hard. Let's work hard, let's try it again." If we're doing a drill, you know, we're missing layups, "Let's start it over. Let's get it right." I don't think there's a 
lot of bad emotion in the gym. It's more, encouraging and challenging them to be, kind of, the best players they can be. Not running them down or, kind of, breaking down.

Conversely, Participant 1 shared that support tended to be strong when the culture was strongest. Meanwhile, when the culture was not as strong, you might instead see people going after each other or undercutting each other.

\section{Bringing Respect to Life}

Coaches talked about treating each other with respect and wanting the studentathletes' time in college to be a positive experience. One element of creating respectful relationships came via the ways in which people communicated with each other, with several coaches mentioning that their current generation of student-athlete would benefit from enhanced communication skills. Given the pervasiveness of technology - and this generation not knowing a world without cell phones - face-to-face communication is sometimes a challenge. Participant 4 painted a vibrant word picture of her team being respectful of team time and the need to communicate with others; in fact the team felt so strongly about it that they did not need anyone to suggest it to them - they developed the idea themselves:

The team had decided they didn't want cell phones at the dinner table. So if you were out as a team, then you left the cell phones on the bus. They really wanted to connect; that was something that they came up with, and they liked, and that has been a standard with the team from now on [emphasized]. And I don't even say anything. We get in the bus and we stop to eat, you'll hear someone in the back say, "Put your phones away. It's Team Time."

In contrast, treating each other in a harsh or abrasive manner would be indicative of not living this value. Participant 4 shared a story about a player who, unhappy with playing time, 
engaged in some "ruthless" behaviors directed at teammates and coaches, which ultimately led to the coach removing the player from the team. Similarly, Participant 5 shared an example from several years ago in which certain members of the team felt that incoming international recruits were being brought in to take their jobs, ultimately leading to a divided team and a culture that had gotten "so competitive it was corrosive." To combat the dysfunction, she suspended several members of the team - essentially splitting the team. She stated that some quit, while others remained suspended until she felt they could be successfully reintegrated back into the group. She explained that the team came together briefly, winning a conference championship, before another incident derailed their postseason. Challenges notwithstanding, the self-described "learning experience" allowed her to reflect on what had happened that season and grow as a coach. She related that, years later, following intentional efforts to reset the culture as well certain student-athletes' graduation, she could see the growth in the program. Contrasting this previous experience, she was told, "Bring us back someone that can help us win" before heading out on an international recruiting trip a couple of years later. 


\section{DISCUSSION}

The purpose of this investigation was to gain a deeper understanding of head coaches' perceptions and experiences leading sustained elite-performing programs. Specifically, the study aimed to understand the role of core values and the ways in which they are taught, lived, and reinforced to drive these cultures. Through an inductive phenomenological approach, coaches described values that emphasized well-being, character, and relationships in addition to optimizing performance. Coaches emphasized the importance of consistent, intentional, daily effort to teach the values as well as to embed them deeply within their programs.

\section{A Look at Culture and Core Values}

Schein defined organizational culture as "the accumulated shared learning of a group as it solves its problems of external adaptation and internal integration; which has worked well enough to be considered valid and, therefore, to be taught to new members as the correct way to perceive, think, feel, and behave in relation to those problems" (Schein \& Schein, 2017). This definition was reflected by the head coaches' responses in the current investigation. Culture was described by one participant as "a melting pot of all people coming together to follow a set way that you can agree upon." Bringing that to life, coaches and student-athletes collaborated to establish definitions of core values and outline acceptable ways to live them. When the culture was challenged, this shared understanding became a touchstone for solving problems. Moreover, the coaches described that these principles were viewed as correct not only to them, but also to the student-athletes, establishing them as worthy of persisting.

Schein further proposed a three-level model for analyzing culture, composed of artifacts, espoused beliefs and values, and taken-for-granted underlying assumptions (Schein, 1990; Schein \& Schein, 2017). Coaches provided insight into each of these levels of culture 
within their programs. The most visible and prominent level of a culture can be seen in its artifacts. Artifacts can come in myriad forms including, dress code, facilities, and history. Coaches described having historical artifacts throughout their facilities as they honored past team and individual successes, as well as key personnel. Likewise, coaches utilized gear like shirts and an honorary scrimmage vest to serve as visible reminders of people embodying desired qualities. Further, coaches utilized signage and sayings that were symbolic throughout program history, as well as providing space for artifacts that were meaningful for a particular year's team.

The second level of cultural analysis in Schein's model (Schein, 1990; Schein \& Schein, 2017) - and the focal point of this investigation - espoused beliefs and values, referred to the qualities, norms, or philosophies stated as primary. In the current study, coaches spoke of values connected with personal and athletic excellence and growth, as well as ways in which members of the group related to each other. More Than Just the Game values highlighted desires to positively affect student-athletes in their athletic pursuits, but also to provide them with principles and skills that could serve them off the field and throughout their lives. Coaches aimed to create environments that provided their athletes with means to pursue excellence, continue to grow and mature, embrace that hard work is often required for something worthwhile, and act with integrity. Likewise, Our Family reflected that ways in which everyone in the culture was expected to connect with each other. Coaches stressed the importance of collaboration, authenticity, respect, and support.

As these values were tested and revealed themselves as effective at solving problems, they became taken-for-granted cultural assumptions - the final level of Schein's three-level model (Schein, 1990; Schein \& Schein, 2017). Evidence of values becoming more deeply embedded within the culture was visible in the way athletes took the lead in addressing 
teammates that deviated from their values or in encouraging each other to leave their cell phones on the bus for "Team Time." Participant 3 described another example of the values becoming more deeply embedded within the program when she explained that she would start to hear student-athletes using cultural sayings and language during media interviews.

Despite being described separately in these paragraphs, there was overlap in the way these three levels presented in the real world. As an example, academic success was part of the larger subtheme Pursuing Excellence. Coaches publicly praised individuals embodying this principle, with one also giving out shirts. These actions and artifacts served to reinforce the importance of doing well in the classroom and strengthen their importance. In doing so, the idea of academic excellence becomes engrained in the culture and understood as an inherent part of the way things are done. This process mirrors a process described by Schein (Schein, 1990; Schein \& Schein, 2017) in which the levels of culture feed into each other to solidify their place in the culture.

Despite all coaches speaking passionately about their respective core values and their importance guiding culture, this was not to suggest that coaches diminished the importance of talent. In fact, all coaches spoke very clearly about the need to have talent and that winning championships cannot happen without it. However, the coaches felt that talent was not enough to build a program capable of sustaining elite performance; even though talent was important, coaches felt that their cultures (driven by core values) were ways to sure up other areas; this assertion has been mirrored in the literature (Schroeder, 2010; Wagstaff, 2019). Coaches stated that talented teams could overcome a poor culture to an extent, but that it would "catch up with you eventually." Moreover, aligned with coaches' emphasis on being about more than just the game, Participant 5 stated that you could win without the character elements embedded in 
this investigation's findings, but not "what I would call 'Winning Big.'” Culture was a way to strengthen areas within the program to help optimize performance, as well as grow people.

Barney (1986) asserted that culture could be a competitive advantage. While the specific cultural elements asserted by Barney were not directly assessed in the current study, coaches did offer insight into potential aspects of their cultures that differed from their peers' cultures. For example, coaches in the current investigation described that they were intentional with doing things their peers might overlook. Participant 1 , as example, talked at length about things she does to empower her teams and lead them with empathy and compassion. She noted that other coaches may find it more effective to simply tell their athletes what to do, while others may find it easier to lead through intimidation and fear. However, Participant 1 talked about her concern for the lifelong effects of leading in that way and suggested that she was willing to invest the time for the benefit of her student-athletes - even when it was more timeconsuming and intensive. While this author cannot speak to specific cultures beyond the scope of this investigation, a lack of consistency and intentionality have been suggested as reasons that cultures may weaken and distinguish themselves from higher-achieving competitors (Abdullah et al., 2011; Barrett, 2006; Collins \& Porras, 1996; Jourdain \& Chênevert, 2015).

Meanwhile, strong cultures have been suggested to play a role in helping organizations handle short-term volatility (Sørensen, 2002). Participant 4 spoke directly to this when she shared her story about a student-athlete participating in "ruthless" behaviors directed at teammates and coaches. Following the player's removal, she claimed that the team grew stronger and more cohesive and went on to play in the Women's College World Series with a walk-on starting. The message from situations like that, Participant 4 said, was that "if you're strong enough culture-wise, you can take a hit. And your bump in the road is very mild ... it's a little speed bump, you get over it, and move on." 


\section{Core Values on the Page and into Action}

Coaches felt that core values served as a navigational system and a guiding compass for helping direct attention and intention to the things considered appropriate, tolerable, and important within the culture. Their description of culture was of similar tone and importance to previous research (Abreu et al., 2009; Lencioni, 2002; Margulies \& Raia, 1988; Oh et al., 2018; Pant \& Lachman, 1998; Sueldo \& Streimikiene, 2016; Williams, 2002). Findings in the present study identified two main themes of core values, each with four subthemes. The first theme, More Than Just the Game, and its subthemes (Pursuing Excellence, Continuous Improvement, Work Ethic is Essential, and Act with Integrity) focused on personal qualities both on the field and off. The second theme, Our Family, and its subthemes (Collaborating with Each Other, Authentically You, Supporting Each Other, and Respecting Each Other) was built around the ways in which people treated each other and fostering effective, cohesive, and collaborative relationships. These identified core values were in line with previous research looking at culture in sport (Cooper et al., 2014; Frontiera, 2010; Jones, 2002; Schroeder, 2010).

Oh and colleagues (2018) identified three key features of core values: first, they are based on organizational culture that builds cohesion with the organization; second, they are practical principles guiding employees' behavior and decision-making; third, they are shared beliefs among an organization's employees that relate to organizational goals and objectives. Coaches' descriptions of their cultures and core values suggested alignment with these features. First, the core values themselves were reflective of all three features. Participant 1 made the connection clear between these features and More Than Just the Game values with her rhetorical question, "Is that celebrating your greatness?" Not only does this make clear the goals and objectives of being a high performer on and off the field, but guides decision-making on whether a multitude of decisions that student-athletes make (e.g., skipping class or getting 
appropriate sleep) are moving them closer to greatness or further from it. Moreover, the Our Family values strongly reflect a desire for cohesion within the culture. Additionally, the coaches' inclusive approach to defining core values suggested that the values were effective guides for decision-making and related to organizational objectives. Coaches referred back to the core values as cultural touchstones when behaviors deviated from principles. And, as Participant 2 described, not only did the coaches think they were the right things, but "the kids think they're the right things."

"Words are words. So, you know, you could say whatever you want, but are you stepping out on those words? Are you moving forward in action? And I think that defines your culture." With this statement, Participant 1 identified the crucial next step: taking the values off the page and bringing them into action. Participant 5 described this process through the colorful metaphor of a fishbowl. She said that there are many groups that might claim to have certain values (the goldfish bowl itself), but without intention to see that the values are being brought to life the water can get murky inside the beautiful bowl. Indeed, previous research has suggested that values lacking clarity and follow-through can stagnate or be abandoned, which can undermine leadership (Cooper et al., 2014; Ferguson \& Milliman, 2008; Hutchinson \& Bennett, 2012; Jollands et al., 2015; Lencioni, 2002). Coaches were very clear on the importance of consistent intentional effort in conveying the desired values and actions, as well as embedding them into multiple areas of the program to avoid their becoming hollow words. From Participant 4's joining student-athletes at camps and clinics to Participant 2's utilization of sport psychology meetings to enhance communication throughout the program to Participant 1 's empowering student-athletes to lead film sessions, coaches in the current investigation were deliberate in their intent to bring the values to life. 
Byrtek and Dickerson (2013) identified a nine-step process for implementing values within an organization. It is worth noting that the authors' model was evaluating the introduction of a new value within an existing culture (which was not specifically a part of the current investigation). However, core values are being constantly being taught (and re-taught) within these coaches' existing cultures given year-to-year roster turnover. The authors' steps overlapped with the findings from the current investigation as well as previous research looking at culture in sport (Frontiera, 2010; Schroeder, 2010). The first step in their model, assessment and understanding of current cultural context, was not expressly observed in the current study, both due to its focus on new value introduction as well as the tenures with which these coaches have been leading their programs. However, the coaches' open lines of communication with their student-athletes and the annual collaborative value definition processes seem to account for contextual factors that this first step is intended to address. Though the core values, themselves, may not be new to returning and veteran student-athletes, they may potentially be new to incoming members of the group (e.g., freshmen or transfers) and this is the lens through which the following steps will be viewed.

The next two steps in the model were Articulation and Definition. In these steps, leaders clearly articulated the core value(s) and defined it through the establishment of a common meaning and role expectations. The findings of the current study suggested alignment with these two steps. Coaches taught and defined their cultural values in two primary ways, Putting Them on Paper and Defining Values Together, with two coaches also utilizing Early Introduction and Teammates Teaching. Utilizing these methods, coaches were able to make sure athletes clearly understood the values the underlie the culture. Books, manuals, and written documents explained central concepts within the culture. Further, previous research has advocated for the development of shared values definitions (Schein \& Schein, 2017; Thyssen, 2009). In the current 
investigation, coaches actively collaborated with their student-athletes in the process of defining what living the core values should look like for themselves. At times, this also included the development of mantras to emphasize specific elements prized by specific year's teams within the larger framework of the program and its values; this process was similar to one described in the business literature as helping organizations remain adaptive (Collins \& Porras, 1996). Moreover, Participant 5 described utilizing veteran team members to formally teach the next generation; previous sport literature has described using teammates to teach culture (Cruickshank et al., 2013).

The fourth step was Active Modeling. Leaders' acting in accordance with values sends a powerful message about the values' importance (Kottke \& Pelletier, 2013; Warrick, 2017). Byrtek and Dickerson (2013) defined modeling in their study with two observable dimensions: leader behaviors that were congruent with the value and leader decisions that demonstrated the value's importance. Coaches spoke at length about the need to model the desired behaviors for both of these reasons. Coaches spoke specifically about the need to model respectful interactions with student-athletes, being on time, being well prepared, and demonstrating a strong work ethic for their student-athletes. This idea of "walking the talk" has been supported in other cultural sport literature (Frontiera, 2010; Schroeder, 2010). Participant 3 felt, "Your players are going to believe more what they see than what you tell them. If you're telling them to be on time and you're late, you're not setting a good example. If you're telling them to be positive and you're yelling at them, I mean, you just want to set a good example."

The next three steps, Stakeholder Engagement and Empowerment, System Alignment, and Reinforcement were all evident in myriad ways in the current study. Just a few examples of Stakeholder Engagement and Empowerment in the current investigation included: giving student-athletes input into gameplay and strategy, having the authority to lead video review 
and stop practice, or even responsibilities to lead specific areas of the programs (e.g., community service projects). System Alignment included elements such as eliminating obstacles, challenging existing processes, and creating value-facilitating mechanisms. In addition to communication to identify what would be considered acceptably living the value, coaches described living this step by challenging the core values. As Participant 4 described, "To start to open the lines of communication is to describe [emphasized] and live [emphasized] and challenge [emphasized] the core values. And those words, to me, open up the conversations that epitomize what the season's all about [in terms of being able to successfully live the values]." Finally, coaches utilized both reinforcement and punishment to promote behaviors aligned with core values and to eliminate behaviors not aligned with core values; examples of these coaching behaviors were highlighted throughout the previous chapter.

Interestingly, the final two steps in Byrtek's and Dickerson's (2013) process were largely not observed in the current study. Byrtek and Dickerson advocated for assessment of the core values, as indicated by Creation of Measures and Measuring and Monitoring. With one exception, coaches did not have any formal mechanisms for measuring core value integration. Instead, coaches described monitoring the degree to which core values had been adopted through daily interaction with and observation of their student-athletes. The nearest thing to formal measurement described by the coaches was some of them utilizing program-wide reviews in which they met with stakeholders (e.g., student-athletes, coaches, support staff) to discuss all aspects of the program. These reviews were used to openly communicate, give and receive feedback, triangulate information throughout the program, and identify strategies to effectively move forward, but were not specifically focused on core values or culture.

If this is the process for bringing core values to life, or demonstrating values-based actions, then one must consider the flip side: how these programs handle situations in which 
athletes do not act in accordance with values. Corporate examples like Enron and Wells Fargo represent extreme cases of a disconnect between actions and words (Avolio \& Gardner, 2005; Warrick, 2017). Coaches repeatedly reiterated their intent to bring values and cultural ideals to the forefront in countless ways, serving to potentially avoid or minimize some potential issues. When deviations from values did happen, coaches employed multiple strategies to address accountability, which generally took the forms of conversation, review, and separation; these processes for accountability were also seen in previous research (Brown \& Treviño, 2006; Frontiera, 2010; Schroeder 2010).

While these steps were not necessarily presented hierarchically, accountability began with conversation. Beyond communicating values on the front end, coaches established multiple touch points with their athletes to address potential deviations from values, including team meetings, pre- or post-practice briefings, video review, check-ins away from sport, and via multiple staff members; some of these conversations took on a casual feel, while others were described as "very tough." Coaches connected back to core values in these conversations, including at times directly asking their athletes if given actions or behaviors aligned with program values and standards. Moreover, coaches opened space for athletes to communicate amongst themselves about potential disconnects in words and actions - which was often, then, used as a springboard for further conversation. Specifically, Participant 4 highlighted that she would facilitate tough group conversations within her program by sitting back as the moderator. "I don't say a lot. I sit back. I let the awkward moment, in the room, get really awkward and heavy ... if I speak too soon, I let them off the hook. So, I wait and I wait and I wait, and then allof-a-sudden a player will start to speak [emphasized] and it gets really uncomfortable [emphasized]. And then, someone will have to answer to it." This then led to follow-up 
conversations with key people, including potentially those committing the offense or those willing to hold their teammate(s) accountable for it.

In addition to individual or group conversation, coaches also utilized review methods to address accountability, such as reinforcement and punishment, video review, or the provision of feedback. Review included reinforcing and punishing behaviors that deviated from values and program norms. Participant 5, as one example, shared that repetitions were repeated when lines were missed during conditioning workouts. This review process also included video review work with teams - led in some cases by the coaches and in others the student-athletes themselves. Video review was utilized to work through strategy and gameplay, as well as to highlight positive and negative instances of living core values. Participant 2 mentioned, "We'll show video highlights, you know, what worked, what didn't work, goals for [emphasized], goals against. We always try and start off with the mistakes we made and end [emphasized] with the good plays we made ... We try to use examples so that, you know, one person can make a mistake, but everyone can learn from it." Moreover, coaches talked about various review processes in which they assessed their entire programs (both related to core values and culture, as well as other aspects). Coaches connected with all members of their program (e.g., studentathletes, assistant coaches, support staff) to identify and communicate areas of the program that were working well and others that would benefit from improvement. Part of the review process also included developing plans for moving forward; by developing these plans with other people, coaches said it served as accountability to live up to the things they each said they would do.

At the more extreme end of accountability, coaches described situations in which separation from the program was required. Not surprisingly, communication still served as part of this process with coaches describing last chance efforts in which they outlined desirable 
behaviors for student-athletes. Participant 3 described having one such conversation with a student-athlete in which she said, "Look, this is how we do things [here]. This is what we value [here]. And, I'm not seeing it from you. Are you capable of - you know, can we work on this?" At times, this last chance attempt resolved issues; yet at other times, it did not, prompting coaches to make decisions to suspend or remove players from the program. Coaches also described student-athletes making the decision to separate on their own. Sometimes athletes recognized a lack of congruence and made the decision to either withdraw from the program or potentially seek a transfer to another program.

\section{Leading Through Values}

With coaches investing this much effort to establish core values and bring them to life, it is important to consider the ways in which coaches lead through these values. Despite having its foundation of with moral and ethical elements at its core (Bass \& Avolio, 1993; Bass \& Steidlmeier, 1999; Brown \& Treviño, 2006; Gardner \& Avolio, 2005), values-based leadership has expanded to also include congruence between leader's values and organizational values (Fernandez \& Hogan, 2002); evidence of these coaching behaviors was clearly evident in the findings of the current study and has been recommended within the previous sport culture research (Aicher \& Cunningham, 2011; Frontiera, 2010; Trail \& Chelladurai, 2002; Vallée \& Bloom, 2005). Likewise, coaches demonstrated strong evidence of two of the most emphasized elements of values-based leadership: transformational leadership and authentic leadership (Copeland, 2014).

\section{Transformational Leadership}

Transformational leadership refers to leaders' ability to move followers beyond immediate self-interests through idealized influence (charisma), inspiration, intellectual 
stimulation, or individualized concerns. Idealized influence and inspirational leadership are displayed when leaders envision a desirable future, articulate how it can be reached, set an example to follow, set high standards of performance, and show determination and confidence. Leaders display intellectual stimulation when they help followers become more innovative and creative. Leaders show individualized concerns when they pay attention to the developmental needs of followers and support and coach their development (Bass, 1999).

In the current study, coaches demonstrated idealized influence and inspirational leadership in the ways in which they presented compelling images for the future for recruits and their current student-athletes. On the field, coaches could draw on their historical successes to outline a path toward personal and team success as well as, obviously, the ability to win championships. Beyond the playing field, coaches could speak to relationships that they had established over the years with former players, as well as ways in which being a part of the programs helped propel them forward in their post-student-athlete careers. Participant 2 explained that she has held career symposia in which she brought back former student-athletes to share their stories and experiences with current student-athletes. Coaches demonstrated intellectual stimulation in a number of previously described ways, including assigning players responsibility over certain areas of the program and probing conversations that challenge them to think. Participant 5's conversations with her team about the United States Women's National Soccer team and their fight for equal pay, as well as coaches' utilizing their student-athletes for on-field problem-solving are examples of this transformational quality. Likewise, coaches spoke about how leading their programs needed to account for individualized considerations and that “you can't do that on a cookie cutter. You got to get to know each of your people, and what moves them and what inspires them, and what their dreams and hopes are." Coaches also 
talked about having individual plans for their athletes' growth and development within the program - which address both personal and athletic development.

Previous research both within and outside of sport has suggested that leaders utilize both transformational and transactional concepts in their leadership (Bass et al., 2003; Kim, 2009; Sarros et al., 2002; Schroeder, 2010). Transactional leadership qualities refer to an exchange relationship between leader and follower to meet their own self-interests, which may take the form of contingent reward, active management by exception (corrective action taken if follower fails to meet standard), or passive leadership (waiting for problems to arise before taking action, or taking no action at all) (Bass, 1999). However, context is also important in understanding the rationale behind certain behaviors (Shivers-Blackwell, 2004; Yukl, 1999). One could certainly make a case that behaviors like rewarding work ethic with a scrimmage vest or punishing missed lines in conditioning drills, themselves, are of a contingent nature; thus, there is some support for the assertion of coaches in the current investigation utilizing elements of both transactional and transformational leadership. However, broader contextual information would be needed to identify the underlying intent of these coaching behaviors. In this way, it would become clear if these were contingent, transactional behaviors as opposed to holding people accountable to the high performance standards and aspirational aspects of transformational leadership.

Relatedly, the data unsurprisingly revealed that winning had become an expectation within these sustained high-performing cultures. That is not to suggest that anyone in the program felt entitled to win or did not continue to prepare; instead, coaches' responses suggested that with the talented student-athletes in their programs, if they did the right things and acted in accordance with their cultures, winning would be a likely result. An investigation into the tremendously successful New Zealand rugby side, the All Blacks, also revealed that 
winning had emerged as an expectation in their iconic history (Johnson et al., 2013). In fact, coaches in the current investigation talked about the change in expectations being the main difference between their programs now and when they first took them over. As coaches grappled with leading programs with changing expectations, they connected back with these transformational elements, as described by Participant 4:

When we started getting to the point where we were Super Regional pretty consistently or going to the World Series, anything less [emphasized] than that is not as exciting anymore, and we had to really make it exciting. ... If you don't celebrate the little things, and you don't celebrate process and progress, that the end goal is going to be a lot harder to attain and sustain. And that's just why we [emphasized] choose to be a little bit more about the development of the entire person because that's really exciting to see a 17 -year-old kid come in every year and grow. And that's pretty fun to watch as a coach.

\section{Authentic Leadership}

Authentic leaders have been described as having a deep sense of purpose; establishing deep relationships; and who acknowledge their thoughts, emotions and beliefs and act consistently with those inner feelings and beliefs (Gardner et al., 2005; George, 2003). Specific to the current investigation, as head coaches of collegiate programs, coaches have a strong influence over the values of a program and its direction. The coaches spoke repeatedly about the need to be authentic in their leadership and provided several examples of what those values looked like when brought into action within their programs. Participant 5, for example, talked about the importance of personal growth, learning, and development in her own life. These personal values have emerged within her program as she created a book club and challenged 
her student-athletes to consider different perspectives as they wrestled with different issues. Similarly, Participant 2 spoke about not wanting to do "silly stuff" during pregame activities, leading to the development of a sport-specific game. While authenticity permeated each conversation with the coaches, Participant 5 spoke to it most directly, saying, "I think you have to be authentic. You can't be anything but yourself in how you do things." This type of leadership has been described as a key factor for reinforcing organizational values (Jeffery \& John, 2008) and has been advocated in previous sport culture research (Aicher \& Cunningham, 2011; Trail and Chelladurai, 2002).

Further, this idea of value congruence has also been described as important toward employees connecting with organizational values (Ab Hamid, 2015; Abdullah et al., 2012; Abreu et al., 2009; Amis et al., 2002; O’Reilly \& Chatman, 1996; Ogbonna \& Harris, 2000; Posner \& Schmidt, 1993; Schneider \& Bowen, 1993; Warrick, 2017). In the current investigation, coaches included their student-athletes in the process of defining core values to facilitate this congruence and gain deeper buy-in. Coaches also described maintaining constant communication with both their team as a whole, as well as their leadership groups. As challenges or potential cultural threats emerged, coaches and student-athletes could reconnect around finding the best solution and continuing the act in accordance with cultural norms as much as possible.

Previous research into core values suggested the potential for them serving as a control mechanism for the organization (Amis, et al., 2002; Janićijević, 2017; Jollands et al., 2015; Lachman et al., 1994; Simons, 1994). From this perspective, as systems and processes are introduced into an organization and prove themselves valid and successful, they become integrated and shared within the culture, shaping what are considered appropriate perceptions, thoughts, and feelings (Kunda, 1992, 2006; Schein \& Schein, 2017; Van Maanen \& Kunda, 1989). 
Whether certain student-athletes within these programs felt the values were restrictive or not is beyond the scope of this investigation. However, coaches described instances in which the student-athletes, themselves, enforced living the core values with their peers, indicating that the student-athletes found personal connection and meaning in the values ( $O^{\prime}$ Reilly and Chatman, 1996).

\section{Limitations}

Despite its strengths, one limitation to this study is that it only reflects the perceptions of head coaches of the elite performing cultures. Head coaches were targeted for their strong influence over core values and culture at the college level. However, future research should build on these findings by gaining insight into other cultural stakeholders. By gaining the perspectives of assistant coaches, support staff (e.g., strength and conditioning coaches, athletic trainers, sport psychologists, and others), and student-athletes, researchers can triangulate the degree to which these espoused core values are truly adopted and integrated throughout the program's culture.

Similarly, data were collected via telephone interview with coaches. The primary investigator did have an existing relationship with one coach in the sample, but the relationships with the others consisted entirely of this research process; this may have led coaches to potentially be more guarded. Therefore, building on the previous paragraph, a next step in the research process might be to perform a case study within these types of programs; in this design, researchers could be embedded within the culture, develop deeper relationships, observe things on their own, and triangulate their meaning and pervasiveness with greater cultural sensitivity and contextual understanding. 
Finally, these coaches provided deep insight into their programs, core values, and cultures. However, caution should be taken to applying these findings more broadly to head coaches of all sustained elite-performing cultures. These female head coaches lead female team sports that consistently perform at a championship level in Division I athletics. However, as numerous media stories illustrating alternate coaching behaviors can attest, the coaching practices observed in this investigation may not be representative of all head coaches of sustained elite performing cultures.

Despite these limitations, the current investigation marks an important step in gaining a deeper understanding of both head coaches' experiences developing sustained elite performance cultures, as well as the role of core values within them. Stories shared by these head coaches and the emergent themes (More Than Just the Game and Our Family) suggested coaches' efforts toward transformational coaching behaviors and wanting to develop skills in their student-athletes - and relationships with them - that extend well beyond their active playing days in these programs. Additionally, coaches stressed the need to clearly define the core values, something they did collaboratively. Likewise, the coaches stressed the need for consistent, intentional, daily effort to ensure that the values move from being words on a page to becoming taken-for-granted assumptions embedded deeply within such a culture. 


\section{APPENDIX A}

Semi-Structured Interview Guide, Interview 1: Identifying Core Values and Culture

Date of Interview:

Time:

Participant:

Sport:

Coach Gender: Male / Female Athletes' Gender: Male / Female

\section{Questions:}

1. What do "core values" mean to you?

2. Generally, how do you define/describe team culture?

3. How would you describe your program's culture?

4. What are the core values of your program's culture?

5. Why are these specific core values important to you and your program?

6. Have these always been the core values, or has that evolved during your time as a head coach? 


\section{APPENDIX B}

Semi-Structured Interview Guide, Interview 2: Process of Implementing and Reinforcing of Core Values and Culture

Date of Interview:

Time:

Participant:

Sport:

Coach Gender: Male / Female

Athletes' Gender: Male / Female

\section{Questions:}

1. Describe the process by which you introduce incoming student-athletes to your program's core values.

2. If I spent a day in your program, what things would be representative of your program's core values and team culture?

3. If I spent a day in your program, what are some physical or tangible things that identify the core values and culture?

4. What were the signs that suggested to you the culture was strengthening?

5. Tell me a story about a bump in the road to this cultural strengthening. What did you do?

6. How do you evaluate the degree to which the core values have taken hold?

7. How do core values and culture (if at all) factor into recruiting? 


\section{APPENDIX C}

Semi-Structured Interview Guide, Interview 3: Larger Meaning of Core Values and Culture

Date of Interview:

Time:

Participant:

Sport:

Coach Gender: Male / Female

Athletes' Gender: Male / Female

\section{Questions:}

1. Can you describe how the core values are related to feedback within your culture?

2. How would you characterize the relationships among your student-athletes? With the coaches?

3. Can you talk to me about the role of competition within your program?

4. How do you balance developing relationships with developing competition?

5. How do you think culture is related to performance? In what ways (if at all) were there cultural differences between your teams that won championships and those that did not?

6. How do you buffer against complacency?

7. In what ways (if at all) are the challenges of leading a program different now than when the program was climbing the ladder?

8. How often is winning discussed within your program?

9. Is there anything else you'd like to share that I have not asked? 


\section{APPENDIX D}

Table 1. Themes and Subthemes of Core Values for the Sustained Elite-Performing Cultures

\begin{tabular}{|c|}
\hline More Than Just the Game \\
\hline Pursuing Excellence \\
\hline Academic excellence \\
\hline Competitive excellence \\
\hline Focus \\
\hline Passion \\
\hline Smart decisions \\
\hline On the field (e.g., strategy/gameplay) \\
\hline Off the field (e.g., nutrition, sleep, alcohol) \\
\hline Continuous improvement \\
\hline Evolution \\
\hline Feedback \\
\hline Growth \\
\hline Learning \\
\hline Work Ethic is Essential \\
\hline Effort \\
\hline Hard work \\
\hline Preparation \\
\hline Acting with Integrity \\
\hline Dependable \\
\hline Honest \\
\hline Punctual \\
\hline Our \\
\hline Family \\
\hline Collaborating with Each Other \\
\hline Communication \\
\hline Empowerment \\
\hline Leadership \\
\hline Unselfish \\
\hline Working together \\
\hline Authentically You \\
\hline Alignment \\
\hline Modeling \\
\hline Trust \\
\hline Vulnerability \\
\hline Supporting Each Other \\
\hline Camaraderie \\
\hline Direct (yet not demeaning) feedback \\
\hline
\end{tabular}




\author{
Encouragement \\ Mentorship \\ Respecting Each Other \\ Communication \\ Compassion \\ Empathy
}




\section{REFERENCES}

1. Ab Hamid, M. R. B. (2015). Value-based performance excellence model for higher education institutions. Quality and Quantity, 49(5), 1919-1944.

2. Abdullah, M., Ab Hamid, M. R., Mustafa, Z., Husain, N., Idris, F., Suradi, N. R. M., \& Ismail, W. R. (2012). Value-based total performance excellence model: A conceptual framework for organisations. Total Quality Management, 23(5), 557-572.

3. Abdullah, M., Ab Hamid, M. R., Mustafa, Z., Suradi, N. R. M., Idris, F., Liong, C.-Y., Ismail, W. R., \& Shahabuddin, F. A. (2011). Value-based total performance excellence measurement (VBTPEM): An overview of agenda and transformation. Journal of Quality Management and Analysis, 7(1), 67-75.

4. Abreu, A., Macedo, P., \& Camarinha-Matos, L. M. (2009). Elements of a methodology to assess the alignment of core-values in collaborative networks. International Journal of Production Research, 47(17), 4907-4934.

5. Aicher, T. J. \& Cunningham, G. B. (2011). Organizational culture and sex impact leader prototypicality and effectiveness. International Journal of Sport Management, 12(3) 344-360.

6. Amis, J., Slack, T., \& Hinings, C. R. (2002). Values and organizational change. The Journal of Applied Behavioral Science, 38(4), 436-465.

7. Andersen, J. A. (2011). A new sports manager does not make a better team. International Journal of Sports Science \& Coaching, 6(1), 167-178.

8. Annells, M. (1999). Evaluating phenomenology: usefulness, quality, and philosophical foundations. Nurse Researcher, 6(3), 5-19.

9. Avolio, B. \& Gardner, W. (2005). Authentic leadership development: Getting to the root of positive forms of leadership. The Leadership Quarterly, 16(3), 315-338. 
10. Bamford, M., Wong, C. \& Laschinger, H.K.S. (2013), "The influence of authentic leadership and areas of worklife on work engagement of registered nurses. Journal of Nursing Management, 21(3), 529-540.

11. Barchiesi, M. A. \& La Bella, A. (2014). An analysis of the organizational core values of the world's most admired companies. Knowledge and Process Management, 21(3), 159-166.

12. Barney, J. B. (1986). Organizational culture: Can it be a source of sustained competitive advantage? The Academy of Management Review, 11(3), 656-665.

13. Barrett, R. (2006). Building a values-driven organization: A whole system approach to cultural transformation. Burlington, MA: Butterworth/Heinemann.

14. Bass, B. M. (1985). Leadership and performance beyond expectations. New York, NY: Free Press.

15. Bass, B. M. (1999). Two decades of research and development in transformational leadership. European Journal of Work and Organizational Psychology, 8(1), 9-32.

16. Bass, B. \& Avolio, B. (1993). Multifactor leadership questionnaire. Palo Alto, CA: Consulting Psychologists Press.

17. Bass, B. M., Avolio, B. J., Jung, D. I., \& Berson, Y. (2003). Predicting unit performance by assessing transformational and transactional leadership. Journal of Applied Psychology, 88(2), 207.

18. Bass, B. \& Steidlmeier, P. (1999). Ethics, character, and transformational leadership behavior. The Leadership Quarterly, 10(2), 81-217.

19. Boeije, H. (2010). Analysis in qualitative research. London, UK: Sage Publications Ltd.

20. Bormann, K. C., \& Rowold, J. (2016). Transformational leadership and followers' objective performance over time: Insights from German basketball. Journal of Applied Sport Psychology, 28(3), 367-373. 
21. Brown, M. \& Treviño, L. (2006). Ethical leadership: A review and future directions. The Leadership Quarterly, 17(3), 595-616.

22. Burns, L. M. (1978). Leadership. New York, NY: Harper \& Row.

23. Byrtek, G. J. \& Dickerson, M. (2013). Actualizing organizational core values: Putting theory into practice. Business Management Dynamics, 3(2), 7-25.

24. Callow, N., Smith, M. J., Hardy, L., Arthur, C. A., \& Hardy, J. (2009). Measurement of transformational leadership and its relationship with team cohesion and performance level. Journal of Applied Sport Psychology, 21(4), 395-412.

25. Carpenter, L. (2017, June 13). The Warriors would be lesser champions without Steve Kerr's gift for joy. The Guardian. Retrieved from https://www.theguardian.com/sport/blog/2017/jun/13/golden-state-warriors-stevekerr-nba-championship

26. Carron, A.V., Bray, S.R., \& Eys, M.A. (2002). Team cohesion and team success in sport. Journal of Sports Sciences, 20(2), 119-126.

27. Charbonneau, D., Barling, J., \& Kelloway, E. K. (2001). Transformational leadership and sports performance: The mediating role of intrinsic motivation. Journal of Applied Social Psychology, 31(7), 1521-1534.

28. Chatman, J. A., Caldwell, D. F., O'Reilly, C. A., \& Doerr, B. (2014). Parsing organizational culture: How the norm for adaptability influences the relationship between culture consensus and financial performance in high-technology firms. Journal of Organizational Behavior, 35(6), 785-808.

29. Chen, C.C. (2013). How does paternalistic style leadership relate to team cohesiveness in soccer coaching? Social Behavior and Personality, 41(1), 83-94. 
30. Christensen, M., Welch, A., \& Barr, J. (2017). Husselian descriptive phenomenology: A review of intentionality, reduction and the natural attitude. Journal of Nursing Education and Practice, 7(8), 113-118.

31. Clark, A. (1998). The qualitative-quantitative debate: Moving from positivism and confrontation to post-positivism and reconciliation. Journal of Advanced Nursing, , $1242-1249$.

32. Clark, B. R. (1972). The organizational saga in higher education. Administrative Science Quarterly, 17(2), 178-184.

33. Collins, J. C. \& Porras, J. I. (1996). Building your company's vision. Harvard Business Review, 74(4), 65-77.

34. Cooper, C. G., Weight, E. A., Pierce, D. (2014). The leader-value continuum: NCAA division I core values and transformational leadership. International Journal of Sport Management, 15(2), 151-171.

35. Copeland, M. K. (2014). The emerging significance of values based leadership: A literature review. International Journal of Leadership Studies, 8(2), 105-135.

36. Corbin, J. \& Strauss, A. (2015). Basics of qualitative research: Techniques and procedures for developing grounded theory (4th ed.). Thousand Oaks, CA: Sage Publications, Inc.

37. Costanza, D. P., Blacksmith, N., Coats, M. R., Severt, J. B., \& DeCostanza, A. H. (2016). The effect of adaptive organizational culture on long-term survival. Journal of Business and Psychology, 31(3), 361-381.

38. Creswell, J. W. (2013). Qualitative inquiry and research design: Choosing among five approaches (3rd ed.). Thousand Oaks, CA: Sage Publications, Inc. 
39. Cronin, L. D., Arthur, C. A., Hardy, J., \& Callow, N. (2015). Transformational leadership and task cohesion in sport: The mediating role of inside sacrifice. Journal of Sport and Exercise Psychology, 37(1), 23-36.

40. Cruickshank, A. \& Collins, D. (2012). Culture change in elite sport performance teams: Examining and advancing effectiveness in the new era. Journal of Applied Sport Psychology, 24(3), 338-355.

41. Cruickshank, A., Collins, D., \& Minten, S. (2013). Culture change in a professional sports team: Shaping environmental contexts and regulating power. International Journal of Sports Science \& Coaching, 8(2), 271-290.

42. Cruickshank, A., Collins, D., \& Minten, S. (2014). Driving and sustaining culture change in Olympic sport performance teams: A first exploration and grounded theory. Journal of Sport and Exercise Psychology, 36(1), 107-120.

43. Cruickshank, A., Collins, D., \& Minten, S. (2015). Driving and sustaining culture change in professional sport performance teams: A grounded theory. Psychology of Sport and Exercise, 20, 40-50.

44. Curtis, B. (2003). The men of March: A season inside the lives of college basketball coaches. Lanham, MD: Taylor Trade.

45. Curtis, B. (2004). Every week a season. Lanham, MD: Taylor Trade.

46. Dahlberg, K., Dahlberg, H., \& Nyström II, M. (2008). Reflective Lifeworld Research, 2nd ed. Studentlitteratur: Lund, Sweden.

47. Deci, E. L., \& Ryan, R. M. (2000). The "what" and "why" of goal pursuits: Human needs and the self-determination of behavior. Psychological Inquiry, 11(4), 227-268.

48. Denison, D. R., \& Mishra, A. K. (1995). Toward a theory of organizational culture and effectiveness. Organization Science, 6(2), 204-223. 
49. Dowling, M. (2007). From Husserl to van Manen. A review of different phenomenological approaches. International Journal of Nursing Studies, 44(1), 131-142.

50. Edvinsson, L. \& Malone, M. S. (1997). Intellectual capital. New York, NY: HarperCollins.

51. ESPN.com (Multiple Contributors). (2018, August 10). The inside story of a toxic culture at Maryland football. ESPN.com. Retrieved from https://www.espn.com/collegefootball/story/_/id/24342005/maryland-terrapins-football-culture-toxic-coach-dj-durkin

52. Ferguson, J. \& Milliman, J. (2008). Creating effective core organizational values: A spiritual leadership approach. International Journal of Public Administration, 31(4), 439459.

53. Fernandez, J. \& Hogan, R. (2002). Values based leadership. The Journal for Quality and Participation, 25(4), 25-26.

54. Finegan, J. E. (2000). The impact of person and organizational values on organizational commitment. Journal of Occupational and Organizational Psychology, 73(2), 149-169.

55. Fletcher, D. \& Arnold, R. (2011). A qualitative study of performance leadership and management in elite sport. Journal of Applied Sport Psychology, 23(2), 223-242.

56. Fletcher, D., \& Wagstaff, C. R. D. (2009). Organizational psychology in elite sport: Its emergence, application and future. Psychology of Sport and Exercise, 10(4), 427-434.

57. Frontiera, J. (2010). Leadership and organizational culture transformation in professional sport. Journal of Leadership \& Organizational Studies, 17(1), 71-86.

58. Fucillo, D. (2017, January 2). Complete transcript of Jed York's press conference. Niners Nation. Retrieved from https://www.ninersnation.com/2017/1/2/14147602/completetranscript-of-jed-york-press-conference

59. Gagne, M. (2003). Autonomy support and need satisfaction in the motivation and wellbeing of gymnasts. Journal of Applied Sport Psychology, 15(4), 372-390. 
60. Gardner, W. \& Avolio, B. (Eds.) (2005). Authentic leadership theory and practice: Origins, effects, and development: Vol 3. Monographs in Leadership Management. New York, NY: Elsevier Science.

61. Gardner, W., Avolio, B., Luthans, F., May, D., \& Walumbwa, F. (2005). Can you see the real me? A self-based model of authentic leader and follower development. The Leadership Quarterly, 16(3), 343-372.

62. Gehman, J., Treviño, L. K., \& Garud, R. (2013). Values work: A process study of the emergence and performance of organizational values practices. Academy of Management Journal, 56(1), 84-112.

63. George, B. (2003). Authentic leadership. San Francisco, CA: Jossey-Bass.

64. Gillet, N., Vallerand, R. J., Amoura, S., \& Baldes, B. (2010). Influence of coaches' autonomy support on athletes' motivation and sport performance: A test of the hierarchical model of intrinsic and extrinsic motivation. Psychology of Sport and Exercise, 11(2), 155-161.

65. Giorgio, A. (1992). Description versus interpretation: Competing alternative strategies for qualitative research. Journal of Phenomenological Psychology, 23 , , 119-135.

66. Glier, R. (2018, July 30). Nick Saban has six new assistants at Alabama - and will probably still win. The New York Times. Retrieved from https://www.nytimes.com/2018/07/30/sports/nick-saban-alabama.html

67. Gochhayat, J., Girl, V. N., \& Suar, D. (2017). Influence of organizational culture on organizational effectiveness: The mediating role of organizational communication. Global Business Review, 18(3), 691-702. 
68. Guba, E. \& Lincoln, Y. (1994). Competing paradigms in qualitative research. In N. Denzin \& Y. Lincoln (Eds.), Handbook of qualitative research (pp. 105-117). Thousand Oaks, CA: Sage.

69. Harter, J., Schmidt, F., \& Hayes, T. (2002) Business-unit level relationship between employee satisfaction, employee engagement, and business outcomes: A meta-analysis. Journal of Applied Psychology, 87(2), 268-279.

70. Hatch, J. A. (2002). Doing qualitative research in educational settings. Albany, NY: State University of New York Press.

71. Hirshleifer, J. (1980). Price theory and its applications (2nd ed.). Englewood Cliffs, NJ: Prentice-Hall.

72. Hofstetter, H. \& Harpaz, I. (2015). Declared versus actual organizational culture as indicated by an organization's performance appraisal. The International Journal of Human Resource Management, 26(4), 445-466.

73. Hollembeak, J. \& Amorose, A.J. (2005). Perceived coaching behaviors and college athletes'intrincis motivation: A test of self-determination theory. Journal of Applied Sport Psychology, 17(1), 20-36.

74. Howard, R. (1990). Values make the company: An interview with Robert Haas. Harvard Business Review, 68(5), 132-144.

75. Hutchinson, M. \& Bennett, G. (2012). Core values brand building in sport: Stakeholder attitudes towards intercollegiate athletics and university brand congruency. Sport Management Review, 15(4), 434-447.

76. Isadore, C. (2014, April 29). What Sterling's ban means for Clipper finances. Retrieved from https://money.cnn.com/2014/04/29/news/companies/sterling-clippersfinances/index.html 
77. Jaiswal, N. K., \& Dhar, R. L. (2015). Transformational leadership, innovation climate, creative self-efficacy and employee creativity: A multilevel study. International Journal of Hospitality Management, 51, 30-41.

78. Jeffery, F. \& John, M. (2008), Creating effective core organizational values: A spiritual leadership approach. International Journal of Public Administration, 31(4), 439-459.

79. Janićijević, N. (2017). Organizational models as configurations of structure, culture, leadership, control, and change strategy. Ekonomski Anali/Economic Annals, 62(213), 67-91.

80. Johnson, T., Martin, A. J., Palmer, F. R., Watson, G., \& Ramsey, P. L. (2013). A core value of pride in winning: The All Blacks' team culture and legacy. The International Journal of Sport and Society, 4(1), 1-14

81. Jollands, S., Akroyd, C., \& Sawabe, N. (2015). Core values as a management control in the construction of "sustainable development". Qualitative Research in Accounting and Management, 12(2), 127-152.

82. Jones, G. (2002). Performance Excellence: A personal perspective on the link between sport and business. Journal of Applied Sport Psychology, 14(4), 268-281.

83. Jourdain, G. \& Chênevert, D. (2015). The moderating influence of perceived organizational values the burnout-absenteeism relationship. Journal of Business and Psychology, 30(1), 177-191.

84. Kemmelmeier, M. \& Kühnen, U. (2012). Culture as a process: The dynamics of cultural stability and change. Social Psychology, 43(4), 171-173.

85. Kent, A., \& Chelladurai, P. (2001). Perceived transformational leadership, organizational commitment, and citizenship behavior: A case study in intercollegiate athletics. Journal of Sport Management, 15(2), 135-159. 
86. Kim, H. (2009). Transformational and transactional leadership of athletic directors and their impact on organizational outcomes perceived by head coaches at NCAA Division II Intercollegiate Institutions (Doctoral dissertation, The Ohio State University).

87. Kim, W. C., \& Mauborgne, R. (2003). Tipping point leadership. Harvard Business Review, 81(4), 60-69.

88. Kontoghiorghes, C. (2016). Linking high performance organizational culture and talent management: Satisfaction/motivation and organizational commitment as mediators. The International Journal of Human Resource Management, 27(16), 1833-1853.

89. Kotter, J. P. (1998). Leading change: Why transformation efforts fail. In J. Collins, J.J. Porras, J. D. Duck, R. Pascale, \& A. Athos (Eds.), Harvard business review on change (pp. 1-20). Cambridge, MA: Harvard Business Review Publishing.

90. Kottke, J. L. \& Pelletier, K. L. (2013). Measuring and differentiating perceptions of supervisor and top leader ethics. Journal of Business Ethics, 113(3), 415-428.

91. Kunda, G. (1992). Engineering culture. Philadelphia, PA: Temple University Press.

92. Kunda, G. (2006). Engineering culture (rev. ed.). Philadelphia, PA: Temple University Press.

93. Lachman, R., Nedd, A., \& Hinings, B. (1994). Analyzing cross-national management and organizations: A theoretical framework. Management Science, 40(1), 40-55.

94. Latham, G. P. \& Pinder, C. C. (2005). Work motivation theory and research at the dawn of the twenty-first century. Annual Review of Psychology, 56, 485-516

95. Lencioni, P. M. (2002). Make your values mean something. Harvard Business Review, 80(7), 113-117. 
96. Leung, D. (2014, December 5). Warriors co-owner Lacob lists reasons for firing Mark Jackson. http://www.mercurynews.com/warriors/ci_27078013/warriors-co-ownerlacob-lists-reasons-firing-mark

97. Leung, D. (2015, December 15). Mark Jackson on not being upset with life after the Warriors: 'I am absolutely winning'.

http://www.ibabuzz.com/warriors/2015/12/10/mark-jackson-on-life-after-the-warriorsi-am-absolutely-winning/

98. Lincoln, Y. S., \& Guba, E. G. (1985). Naturalistic inquiry. Newburry Park: Sage Publications.

99. MacPherson, A. C. \& Howard, P. W. (2011). The team perspective: Promoting excellence in performance teams. In D. Collins, A. Button, \& H. Richards (Eds.), Performance psychology: A practitioner's guide (pp. 121-138). London, UK: Elsevier.

100. Margulies, N. \& Raia, A. (1988). The significance of core values on the theory and practice of organizational development. Journal of Organizational Change Management, 1(1), 6-17.

101. Mills, C., \& Hoeber, L. (2013). Exploring organizational culture through artifacts in a community figure skating club. Journal of Sport Management, 27(6), 482-496.

102. Moore, I. \& Avila, W. (2014, August 19). Timeline: Donald Sterling's ownership of the LA Clippers. Retrieved from https://www.nbcsandiego.com/news/sports/Timeline-Donald-Sterlings-Legal-Troubles-257044581.html

103. NACDA. Accessed 2018, June 27. About the Learfield Director's Cup. Retrieved from http://www.nacda.com/directorscup/nacda-directorscup.html 
104. Ogbonna, E., \& Harris, L. C. (2000). Leadership style, organizational culture and performance: empirical evidence from UK companies. International Journal of Human Resource Management, 11(4), 766-788.

105. Oh, J., Cho, D., \& Lim, D. H. (2018). Authentic leadership and work engagement: The mediating effect of practicing core values. Leadership \& Organization Development Journal, 39(2), 276-290.

106. O’Reilly, C., \& Chatman, J. (1996). Cultures as social control: Corporations, cults, \& commitment. In L. Cummings, \& B. Straw (Eds.), Research in organizational behavior (pp. 157-200), Greenwich, CT: JAI Press.

107. O’Reilly, C. A., Chatman, A. J., \& Caldwell, D. (1991). People and organizational culture: A Q-sort approach to assessing person-organization fit. Academy of Management Journal, 34(3), 487-516.

108. Pain, M. A., \& Harwood, C. (2007). The performance environment of the England youth soccer teams. Journal of Sports Sciences, 25(12), 1307-1324.

109. Pain, M. A., \& Harwood, C. G. (2008). The performance environment of the England youth soccer teams: A quantitative investigation. Journal of Sports Sciences, 26(11), 1157-1169.

110. Pant, N. P. \& Lachman, R. (1998). Value incongruity and strategic choice. Journal of Management Studies, 35(2), 195-212.

111. Paskevich, D.M., Brawley, L.R., Dorsch, K.D., \& Widmeyer, W.N. (1999).

Relationship between collective efficacy and team cohesion: Conceptual and measurement issues. Group Dynamics: Theory, Research, and Practice, 3(3), 210-222.

112. Patton, M. (2002). Qualitative research and evaluation methods (3rd ed.). Thousand Oaks, CA: Sage. 
113. Pelletier, L. G., Fortier, M. S., Vallerand, R. J., \& Brière, N. M. (2001). Associations among perceived autonomy support, forms of self-regulation, and persistence: A prospective study. Motivation and Emotion, 25(4), 279-306.

114. Porter, M. (1980). Competitive strategy. New York, NY: Free Press.

115. Posner, B. Z. \& Schmidt, W. H. (1993). Values congruence and differences between the interplay of personal and organizational value systems. Journal of Business Ethics, 12(5), 341-347.

116. Price, M.S. \& Weiss, M.R. (2011). Peer leadership in sport: Relationships among personal characteristics, leader behaviors, and team outcomes. Journal of Applied Sport Psychology, 23(1), 49-64.

117. Racher, F.E. \& Robinson, S. (2003). Are phenomenology and postpositivism strange bedfellows?. Western Journal of Nursing Research, 25(5), 464-481.

118. Rowold, J. (2006). Transformational and transactional leadership in martial arts. Journal of Applied Sport Psychology, 18(4), 312-325.

119. Ryan, R. M., \& Deci, E. L. (2008). Self-determination theory and the role of basic psychological needs in personality and the organization of behavior. In O. P. John, R. W. Robins, \& L. A. Pervin (Eds.), Handbook of personality: Theory and research (pp. 654678). New York, NY: Guilford Press.

120. Ross, J. A. \& Gray, P. (2006). Transformational leadership and teacher commitment or organizational values: The mediating effects of collective teacher efficacy. School Effectiveness and School Improvement, 17(2), 179-199.

121. Saldaña, J. (2016). The coding manual of qualitative researchers (3rd ed.). London, UK: Sage Publications, Ltd. 
122. Sarros, J. C., Cooper, B. K., \& Santora, J. C. (2008). Building a climate for innovation through transformational leadership and organizational culture. Journal of Leadership \& Organizational Studies, 15(2), 145-158.

123. Sarros, J. C., Gray, J., \& Densten, I. L. (2002). Leadership and its impact on organizational culture. International Journal of Business Studies, 10(2), 1-25.

124. Schein, E. H. (1990). Organizational culture. American Psychologist, 45(2), 109119.

125. Schein, E. H. (2006). Organizational culture and leadership. San Francisco, CA: Jossey-Bass.

126. Schein, E. H. (2010). Organizational culture and leadership (4th ed.). San Francisco, CA: Jossey-Bass.

127. Schein, E. H. \& Schein, P. (2017). Organizational culture and leadership (5th ed.). Hoboken, NJ: John Wiley \& Sons.

128. Schlabach, M. (2007, August 30). Virginia Tech's lunch pail holds a reminder of the strength of Hokie nation. Retrieved from http://www.espn.com/collegefootball/columns/story?columnist=schlabach_mark\&id=2997449

129. Schneider, B. \& Bowen, D. E. (1993). The service organization: Human resources management is crucial. Organizational Dynamics, 21(4), 39-52.

130. Schroeder, P. J. (2010). Changing team culture: The perspectives of ten successful head coaches. Journal of Sport Behavior, 32(4), 63-88.

131. Seidman, I. (2013). Interviewing as qualitative research (4th ed.). New York, NY: Teachers College Press. 
132. Shivers-Blackwell, S. L. (2004). Using role theory to examine determinants of transformational and transactional leader behavior. Journal of Leadership \& Organizational Studies, 10(3), 41-50.

133. Sihombing, S., Astuti, E. S., Al Musadieq, A., Hamied, D., \& Rohardjo, K. (2018). The effect of servant leadership on rewards, organizational culture, and its implication for employee performance. International Journal of Law and Management, 60(2), 505516.

134. Simons, R. (1994). How new top managers use control systems as levers of strategic renewal. Strategic Management Journal, 15(3), 169-189.

135. Smircich, L. (1983). Concept of culture and organizational analysis. Administrative Science Quarterly, 28(3), 339-358.

136. Smith, A. C., \& Shilbury, D. (2004). Mapping cultural dimensions in Australian sporting organisations. Sport Management Review, 7(2), 133-165.

137. Smith, M. J., Arthur, C. A., Hardy, J., Callow, N., \& Williams, D. (2013). Transformational leadership and task cohesion in sport: The mediating role of intrateam communication. Psychology of Sport and Exercise, 14(2), 249-257.

138. Sørensen, J. B. (2002). The strength of corporate culture and the reliability of firm performance. Administrative Science Quarterly, 47(1), 70-91.

139. Sosis, R. \& Ruffle, B. J. (2004). Ideology, religion, and the evolution of cooperation: Field experiments on Israeli Kibbutzim. In M. Alvard (Ed.), Socioeconomic aspects of human behavior ecology (Research in economic anthropology, volume 23, 89117. Bingley, UK: Emerald Group Publishing Limited. 
140. Steers, R. M., \& Shim, W. S. (2013). Strong leaders, strong cultures: Global management lessons from Toyota and Hyundai. Organizational Dynamics, 42(3), 217227.

141. Sueldo, M. \& Streimikiene, D. (2016). Organizational rituals as tools of organizational culture creation and transformation: A communicative approach. Transformation in Business \& Economics, 15(2), 89-110.

142. Sufi, T., \& Lyons, H. (2003). Mission statements exposed. International Journal of Contemporary Hospitality Management, 15(5), 255-262.

143. Sull, D. (2010). Are you ready to rebound? Harvard Business Review, 88(3), 7074.

144. Thompson, J. (Host). (2016, August 18). PCA Development Zone [Audio Podcast]. Retrieved from https://devzone.positivecoach.org/resource/audio/steve-kerrs-4-corevalues-joy-mindfulness-compassion-competition

145. Thyssen, O. (2009). Business ethics and organizational values: A systemstheoretical analysis. Basingstoke, UK/New York, NY: Palgrave Macmillan.

146. Trail, G., \& Chelladurai, P. (2002). Perceptions of intercollegiate athletic goals and processes: The influence of personal values. Journal of Sport Management, 16(4), 289-310.

147. Tuckman, B. W. (1965). Developmental sequence in small groups. Psychological Bulletin, 63(6), 384-399.

148. Tushman, M., \& O’Reilly, C. (1997). Winning through innovation: A practical guide to leading organizational change and renewal. Boston, MA: Harvard Business School Press 
149. Urde, M. (2003). Core value-based corporate brand building. European Journal of Marketing, 37(7/8), 1017-1040.

150. Vallée, C. N., \& Bloom, G. A. (2005). Building a successful university program: Key and common elements of expert coaches. Journal of Applied Sport Psychology, 17(3), 179-196.

151. Van Maanen, J. \& Kunda, G. (1989). Real feelings: Emotional expression and organizational culture. In B. Straw (Ed.), Research in organizational behavior (vol. 11, pp. 43-103). Greenwich, CT, JAI Press.

152. Van Rekom, J., van Riel, C. B. M., \& Wierenga, B. (2006). A methodology for assessing organizational core values. The Journal of Management Studies, 43(2), 175201.

153. Viinamäki, O.-P. (2009). Intra-organizational of values-based leadership. Electronic Journal of Business Ethics and Organizational Studies, 14(2), 6-13.

154. Wagstaff, C. R. D., \& Burton-Wylie, S. (2018). Organisational culture in sport: A conceptual, definitional and methodological review. Sport \& Exercise Psychology Review, 14(1), 32-52.

155. Walsh, B. (2010). The score takes care of itself: My philosophy of leadership. New York, NY: Portfolio.

156. Wagstaff, C. R. D. (2019). Taking stock of organizational psychology in sport. Journal of Applied Sport Psychology, 31(1), 1-6.

157. Warrick, D. D. (2017). What leaders need to know about organizational culture. Business Horizons, 60(3), 395-404. 
158. Weese, W. J. (1995). Leadership and organizational culture: An investigation of Big Ten and Mid-American conference campus recreation administrations. Journal of Sport Management, 9(2), 119-134.

159. Weese, W. J. (1996). Do leadership and organizational culture really matter?. Journal of Sport Management, 10(2), 197-206.

160. Weinberg, R. \& McDermott, M. (2002). A comparative analysis of sport and business organizations: Factors perceived critical for organizational success. Journal of Applied Sport Psychology, 14(4), 282-298.

161. Weiszer, M. (2016, January 13). Culture change under new UGA coaching staff may bring 'inevitable' attrition. Athens Banner-Herald, Retrieved from http://www.onlineathens.com/article/20160113/SPORTS/301139970

162. Weston, N.J.V, Greenlees, I.A., \& Thelwell, R.C. (2011). The impact of a performance profiling intervention on athlete's intrinsic motivation. Research Quarterly for Exercise and Sport, 82(1), 151-155.

163. Williams, S. L. (2002). Strategic planning and organizational values: Links to alignment. Human Resource Development International, 5(2), 217-233.

164. Wojnarowski, A. (2018, July 17). Charlotte Hornets coach James Borrego. The Woj Pod. Podcast retrieved from https://art19.com/shows/thewojpod/episodes/e15d4626-1535-4046-89924b46408aea66

165. Wong, C., Laschinger, H. \& Cummings, G. (2010). Authentic leadership and nurses voice behavior and perceptions of care quality. Journal of Nursing Management, 18(8), 889-900. 
166. Yukl, G. (1999). An evaluation of conceptual weaknesses in transformational and charismatic leadership theories. The Leadership Quarterly, 10(2), 285-305.

167. Zimbalist, A. (1998, October 18). The capitalist; A Miami fish story. The New York Times Magazine. Retrieved from https://www.nytimes.com/1998/10/18/magazine/thecapitalist-a-miami-fish-story.html 


\section{VITA}

Eric Biener began his coaching career as an intern within the University of Central Florida strength and conditioning department during his time as an undergraduate there. Following graduation, he went to the University of North Carolina at Chapel Hill for graduate school. Biener began working with North Carolina's strength and conditioning department as a graduate student, earning a full-time staff position following graduation. During his time at North Carolina, Biener was a part of several championship seasons and had the opportunity to work with many elite student-athletes, coaches, and teams. While coaching, Biener began to consider the importance of core values and culture within the teams with which he worked - a curiosity that eventually contributed to this project.

Biener left North Carolina in 2015 to pursue a doctoral degree at the University of Missouri in Educational Psychology with an emphasis in Sport and Performance. Within his work as a graduate student, Biener gained applied performance psychology experiences with the Pittsburgh Pirates professional baseball franchise and at the United States Military Academy (West Point).

This dissertation was typed by the author. 